\title{
Roles of SST versus Internal Atmospheric Variability in Winter Extreme Precipitation Variability along the U.S. West Coast
}

\author{
Lu Dong, L. Ruby Leung, Fengfei Song, And JiAn Lu \\ Atmospheric Sciences and Global Change Division, Pacific Northwest National Laboratory, Richland, Washington
}

(Manuscript received 4 February 2018, in final form 13 July 2018)

\begin{abstract}
The U.S. West Coast exhibits large variability of extreme precipitation during the boreal winter season (December-February). Understanding the large-scale forcing of such variability is important for improving prediction. This motivates analyses of the roles of sea surface temperature (SST) forcing and internal atmospheric variability on extreme precipitation on the U.S. West Coast. Observations, reanalysis products, and an ensemble of Atmospheric Model Intercomparison Project (AMIP) experiments from phase 5 of the Coupled Model Intercomparison Project (CMIP5) are analyzed. It is found that SST forcing only accounts for about $20 \%$ of the variance of both extreme and nonextreme precipitation in winter. Under SST forcing, extreme precipitation is associated with the Pacific-North American teleconnection, while nonextreme precipitation is associated with the North Pacific Oscillation. The remaining 80\% of extreme precipitation variations can be explained by internal atmospheric dynamics featuring a circumglobal wave train with a cyclonic circulation located over the U.S. West Coast. The circumglobal teleconnection manifests from the mid- to high-latitude intrinsic variability, but it can also emanate from anomalous convection over the tropical western Pacific, with stronger tropical convection over the Maritime Continent setting the stage for more extreme precipitation in winter. Whether forced by SST or internal atmospheric dynamics, atmospheric rivers are a common and indispensable feature of the large-scale environment that produces concomitant extreme precipitation along the U.S. West Coast.
\end{abstract}

\section{Introduction}

Extreme precipitation batters the U.S. West Coast during boreal winter [December-February (DJF)] and accounts for $20 \%-60 \%$ of the total winter precipitation along the west coast of North America from north to south (Fig. 1). Although extreme precipitation poses significant risks to human lives and properties, and challenges water management by causing flooding, landslides, and hazards, it provides the much-needed water resources for drought-prone regions that rely on winter snowpack for water supply (e.g., Cayan and Riddle 1992; Cayan et al. 1999; Ralph et al. 2006; Warner et al. 2012; Biasutti et al. 2016). In the western United States, extreme precipitation is largely fueled by landfalling atmospheric rivers (ARs) that transport copious amounts of water vapor from the Pacific Ocean to the mountainous region (e.g., Ralph et al. 2006; Leung and Qian 2009; Neiman et al. 2011). ARs are characterized by high moisture content in the lower troposphere and a

Corresponding author: Lu Dong, lu.dong@pnnl.gov strong low-level jet (Ralph et al. 2004); they are responsible for more than $90 \%$ of the global atmospheric water vapor transport across the midlatitudes (Zhu and Newell 1998; Ralph and Dettinger 2012).

The response of ARs and the concomitant extreme precipitation to global warming has been extensively explored in a series of studies using climate model projections (e.g., Dettinger 2011; Payne and Magnusdottir 2015; Warner et al. 2015; Hagos et al. 2016; Gao et al. 2015, 2016; Shields and Kiehl 2016; Shields et al. 2016). While understanding the future changes of extreme precipitation is important for long-term planning of water resources, wintertime extreme precipitation along the West Coast is marked by significant variability that is not fully understood or adequately simulated by models. Previous studies have provided observational evidence for linking precipitation in North America with El NiñoSouthern Oscillation (ENSO) (e.g., Redmond and Koch 1991; Piechota and Dracup 1996; Dettinger et al. 1998; Yoon and Leung 2015; Jong et al. 2016; Kumar and Chen 2017). However, few studies have quantified the extent to which sea surface temperature (SST) forcing contributes 
(a) DJF daily precipitation Climatology

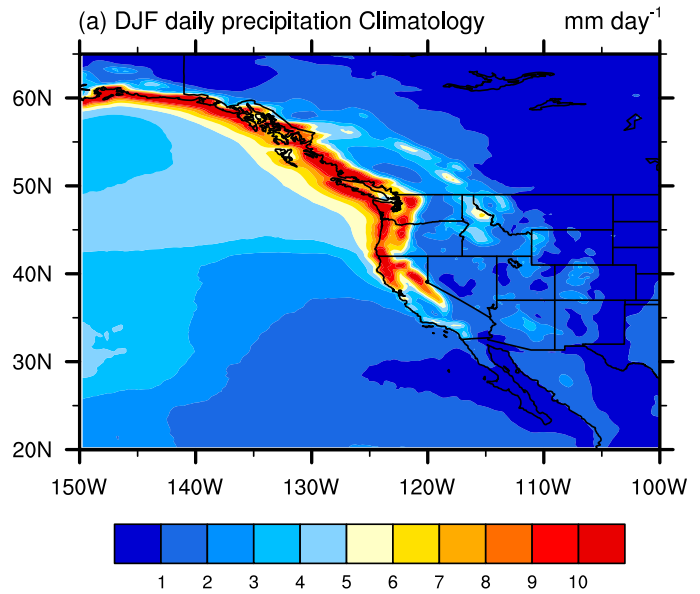

(c) $>95 \%$ total precipitation

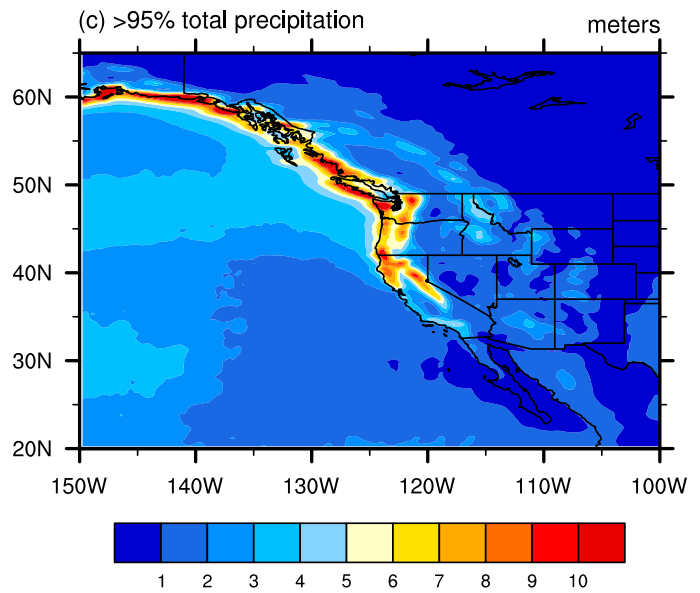

(e) extreme percentages

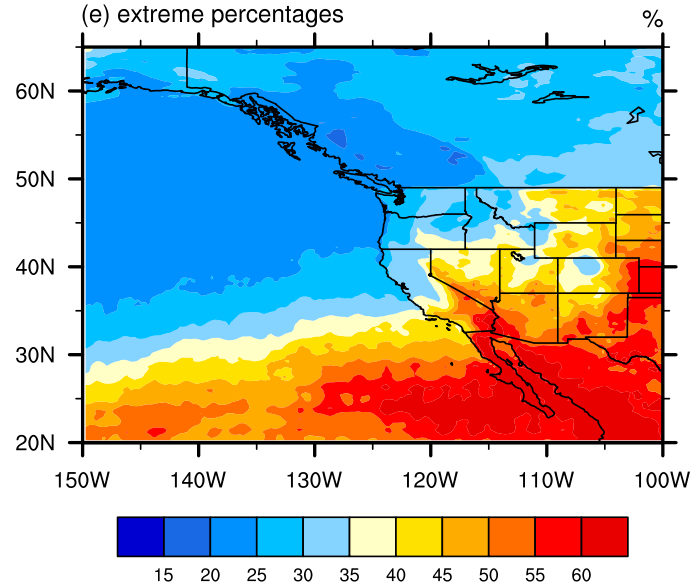

(b) $95 \%$ of DJF daily precipitation

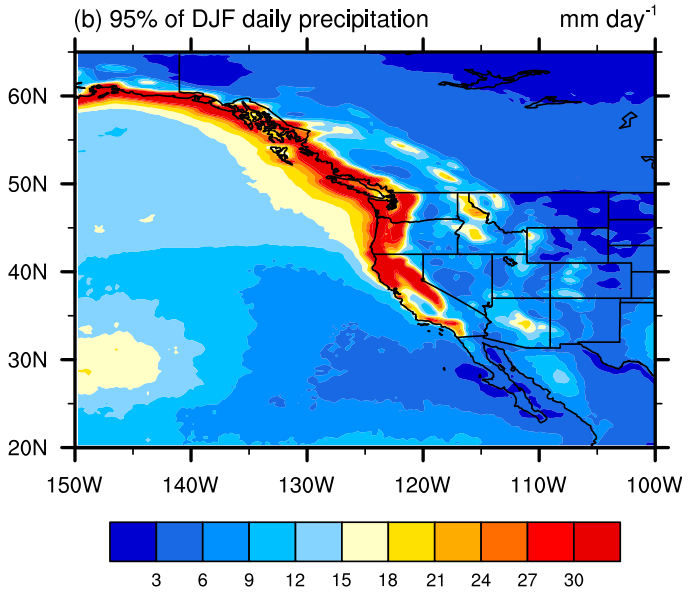

(d) $<=95 \%$ total precipitation
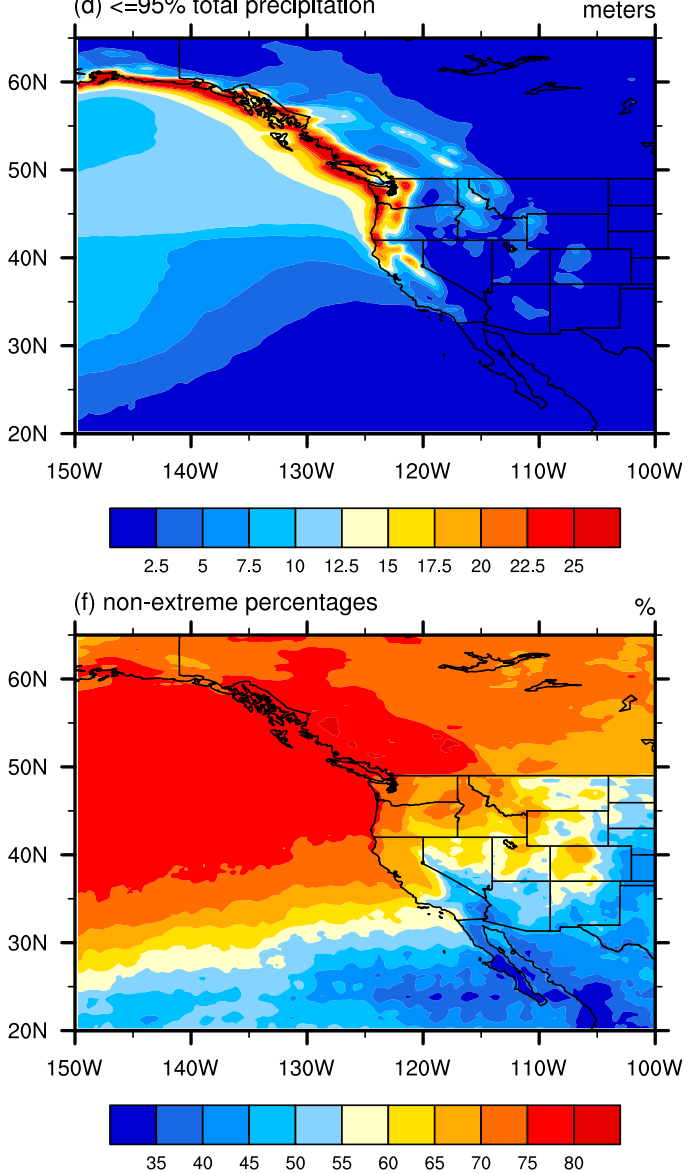

FIG. 1. (a) Climatology of daily precipitation $\left(\mathrm{mm} \mathrm{day}^{-1}\right)$; (b) the extreme precipitation threshold (95th percentile daily precipitation; $\mathrm{mm}_{\text {day }}{ }^{-1}$ ); (c) total extreme precipitation (m); (d) total nonextreme precipitation (below the extreme precipitation threshold; $\mathrm{m}$ ); (e) percentages of extreme precipitation in the total precipitation (\%); (f) percentages of nonextreme precipitation in the total precipitation (\%). Results are based on daily precipitation from NARR during DJF of 1979-2017.

to the variances of winter extreme precipitation in North America (Hartmann 2015; Bond et al. 2015).

In addition to SST forcing, midlatitude teleconnections associated with circumglobal Rossby waves also have important influences on weather extremes such as heat waves, cold air outbreaks, droughts, and precipitation in the United States (Mo and Higgins 1998; Teng et al. 2013; Seager et al. 2015; Harnik et al. 2016; 
Teng and Branstator 2017). Facilitated by the midlatitude tropospheric jets acting as waveguides for the propagation of Rossby waves, the midlatitude waves tend to orient primarily in the zonal direction, navigate circumglobally (Branstator 2002; Ding and Wang 2005), and become significant during boreal winter (Branstator and Teng 2017). Such planetary wave patterns in the midlatitudes arise from internal atmospheric dynamics and can be easily excited by atmospheric forcing in the extratropics (Teng and Branstator 2017). On the other hand, many studies suggest that tropical forcing can also influence precipitation and snowpack along the U.S. West Coast by modulating the North Pacific circulation and ARs (e.g., Higgins and Mo 1997; Mo and Higgins 1998; Bond and Vecchi 2003; Jones 2000; Ralph et al. 2011; Zhou et al. 2012; Guan et al. 2012). In a case study of an AR, Ralph et al. (2011) revealed the role of tropical-extratropical interaction between the MaddenJulian oscillation (MJO) and extratropical wave packets in modulating the water vapor transported by the AR and influencing its landfall over western North America. It is not clear how often and to what extent similar teleconnections between tropical heating and midlatitude circulation may influence AR development in the North Pacific. What is lacking is a more systematic analysis of the role of large-scale atmospheric variability on extreme precipitation over the western United States.

This study explores the large-scale environments that favor U.S. West Coast extreme precipitation during winter (DJF), with a focus on quantifying the roles of SST forcing versus internal atmospheric variability. Also examined are the prominent modes of AR variability in DJF and their modulation of extreme precipitation along the U.S. West Coast. In what follows, we first investigate the climatology and dominant modes of extreme precipitation in DJF along the west coast of North America and examine their relationship with ARs. Using outputs from phase 5 of the Coupled Model Intercomparison Project (CMIP5), the contributions of SST forcing to the DJF variations in extreme precipitation are evaluated, and the large-scale circulations associated with the SST forcing for extreme and nonextreme precipitation are compared. Finally, the sources of internal atmospheric variability that modulate the large-scale environment of extreme precipitation are explored. Our findings identify that SST forcing is not the dominant factor for modulating the year-to-year variances of winter extreme precipitation along the U.S. West Coast. Instead, internal atmospheric dynamics with wave activity over the mid- to high latitudes, including their interactions with tropical forcing, contribute significantly more to the variations in extreme precipitation. In addition, the possible drivers of the record extreme precipitation along the U.S. West Coast during the winter of 2016/17 are discussed.

\section{Observations, model experiments, and methods}

\section{a. Observations and model experiments}

In this study, daily datasets are used to capture the synoptic events of ARs, MJOs, and extreme precipitation. These include precipitation from the North American Regional Reanalysis (NARR) at $32-\mathrm{km}$ resolution (Mesinger et al. 2006), along with specific humidity and zonal and meridional winds from the ECMWF interim reanalysis (ERA-Interim) at a $1.5^{\circ} \times 1.5^{\circ}$ resolution (Dee et al. 2011). To examine the large-scale circulation, convection, and surface temperature anomalies associated with extreme and nonextreme precipitation, we use monthly precipitation from NARR, monthly SST from the Hadley Centre Sea Ice and Sea Surface Temperature dataset (HadISST; $1^{\circ} \times 1^{\circ}$; Rayner et al. 2003), National Oceanic and Atmospheric Administration Extended Reconstructed SST, version 4 (ERSST.v4; $2^{\circ} \times 2^{\circ}$; Huang et al. 2015; Karl et al. 2015), monthly surface air temperature (SAT) from Hadley Centre/Climatic Research Unit near-surface temperature anomaly, version 4 (HadCRUT; $5^{\circ} \times 5^{\circ}$; Morice et al. 2012), NASA GISS Surface Temperature Analysis (GISTEMP; $2^{\circ} \times 2^{\circ}$; Hansen et al. 2010), monthly wind, specific humidity, sea level pressure (SLP), and geopotential height (GPH) from ERA-Interim $\left(1^{\circ} \times 1^{\circ}\right)$ and NCEP-NCAR reanalysis $\left(\mathrm{NCEP} 1 ; 2.5^{\circ} \times\right.$ 2.5'; Kalnay et al. 1996), and monthly outgoing longwave radiation $(\mathrm{OLR})$ from NOAA $\left(2.5^{\circ} \times 2.5^{\circ}\right.$; Liebmann and Smith 1996).

A total of 54 Atmospheric Model Intercomparison Project (AMIP) simulations from 16 CMIP5 models are used in this study. Some details of the model simulations, including the originating institutions, horizontal and vertical resolutions, and number of realizations used in this study, are described in Table 1 and Taylor et al. (2012). In the AMIP experiments, the atmospheric general circulation models (AGCMs) are forced by historical global SST and sea ice data for 1979-2008 (Taylor et al. 2012). The AMIP outputs, including daily precipitation rate, monthly surface temperature, SLP, geopotential heights, and OLR are used for analysis. To calculate the multimember ensemble mean, all the monthly fields in the AMIP runs are interpolated to a common $64 \times 128$ global grid, the lowest resolution of all the models we use (Table 1). We also use the SSTClim run from GFDL CM3, with the same atmospheric model resolution as the AMIP runs from GFDL CM3 shown in Table 1. The CMIP5 datasets used in this study can be obtained at http://www.ipcc-data.org/sim/ gcm_monthly/AR5/Reference-Archive.html. 
TABLE 1. The name, institution, horizontal and vertical resolutions, and number of realizations of each atmospheric model included in the AMIP runs used in this study.

\begin{tabular}{llrr}
\hline \hline \multicolumn{1}{c}{ Model } & \multicolumn{1}{c}{ Institute/Country } & Resolution (lat $\times$ lon, level) & Number of realizations \\
\hline ACCESS1.0 & CSIRO-BoM/Australia & $145 \times 192, \mathrm{~L} 38$ & 1 \\
BCC_CSM1.1 & BCC/China & $64 \times 128, \mathrm{~L} 26$ & 3 \\
BNU-ESM & BNU/China & $64 \times 128, \mathrm{~L} 26$ & 1 \\
CanAM4 & CCCma/Canada & $64 \times 128, \mathrm{~L} 35$ & 4 \\
CCSM4 & NCAR/United States & $192 \times 288, \mathrm{~L} 27$ & 5 \\
CMCC-CM & CMCC/Italy & $240 \times 480, \mathrm{~L} 27$ & 3 \\
CNRM-CM5 & CNRM-CERFACS/France & $128 \times 256, \mathrm{~L} 31$ & 1 \\
CSIRO Mk3.6.0 & CSIRO-QCCCE/Australia & $96 \times 192, \mathrm{~L} 18$ & 10 \\
FGOALS-s2 & IAP-LASG/China & $64 \times 128, \mathrm{~L} 26$ & 3 \\
GFDL CM3 & NOAA-GFDL/United States & $90 \times 144, \mathrm{~L} 48$ & 5 \\
INM-CM4.0 & INM/Russia & $120 \times 180, \mathrm{~L} 21$ & 1 \\
IPSL-CM5A-LR & IPSL/France & $96 \times 96, \mathrm{~L} 39$ & 6 \\
MIROC5 & MIROC/Japan & $128 \times 256, \mathrm{~L} 40$ & 2 \\
MPI-ESM-MR & MPI-M/Germany & $96 \times 192, \mathrm{~L} 96$ & 3 \\
MPI-ESM-LR & MPI-M/Germany & $96 \times 192, \mathrm{~L} 47$ & 3 \\
MRI-CGCM3 & MRI/Japan & $160 \times 320, \mathrm{~L} 48$ & 3 \\
\hline
\end{tabular}

\section{b. Methods}

In this study, we discuss the relative roles of SST and internal atmospheric variability on the precipitation variation over the U.S. West Coast. Because DJF is the peak season for ENSO and the related teleconnections, we focus on DJF to maximize the effect of SST forcing, though November is also one of the wettest months for both extreme and mean precipitation in the U.S. West Coast (not shown). Including November does not change our main conclusions significantly, but the effect of SST forcing on both extreme and nonextreme precipitation is reduced compared with DJF. This suggests that the largest effect of SST forcing on cold season extreme and nonextreme precipitation in the U.S. West Coast occurs in DJF.

Extreme precipitation in boreal winter is defined as precipitation exceeding the 95th percentile of daily precipitation determined from the NARR dataset for the historical period of 1979-2017 for each grid cell during DJF (Hagos et al. 2016). In this study, we refer to the daily precipitation below the 95th percentile threshold as nonextreme precipitation. Only days with daily precipitation amounts larger than $0.01 \mathrm{~mm}$ are considered in the calculation. To analyze the variations of DJF extreme and nonextreme precipitation, the total daily extreme precipitation and nonextreme precipitation $\left(\mathrm{mm} \mathrm{day}^{-1}\right)$ are summed up over each month $\left(\mathrm{mm}\right.$ month $\left.^{-1}\right)$ at each grid point to calculate the average values for DJF, yielding time series of yearly DJF mean values $(\mathrm{mm}$ month $^{-1}$ ). The areal average over the U.S. West Coast $\left(35^{\circ}-50^{\circ} \mathrm{N}, 130^{\circ}-118^{\circ} \mathrm{W}\right)$ is used as extreme and nonextreme precipitation indices, respectively. Note that the present definition of extreme precipitation does not take into account the temporal characteristics of daily precipitation. In the future, it would be interesting and meaningful to look at the more persistent extreme events because of the potentially larger impacts they have on catastrophic events such as flooding and landslides.

Based on Lavers et al. (2012), Warner et al. (2015), and Gao et al. (2016), an AR is defined based on the vertically integrated water vapor transport (IVT) from 1000 to $500 \mathrm{hPa}$ as

$$
\mathrm{IVT}=\sqrt{\left(\frac{1}{g} \int_{1000}^{500} q u d p\right)^{2}+\left(\frac{1}{g} \int_{1000}^{500} q v d p\right)^{2}},
$$

where $g$ represents the gravitational acceleration, $q$ represents the layer mean specific humidity, and $u, v$ represent zonal and meridional winds, respectively. For consistency with the definition of extreme precipitation, ARs are defined by the 95th percentile of daily IVT in each grid determined from the historical period of 19792017 during DJF based on the ERA-Interim. Using the 85th percentile as the cutoff for ARs as in Gao et al. (2016) does not change the main results (not shown). Similar to extreme precipitation, the total IVT transported by ARs is accumulated over each month at each grid, and the average values during DJF are used for analyzing the year-to-year variations in the accumulated features of many ARs.

Internal atmospheric variability is not synchronous across the individual realizations in the AMIP simulations, so their ensemble mean can effectively suppress internal atmospheric variability and isolate the effects of SST forcing. The ensemble mean is calculated as the arithmetic mean of the equally weighted 54 AMIP 
members. We obtain the internal atmospheric component of extreme precipitation variability using two approaches. In the first approach, the internal atmospheric component is calculated as the residual after removing the ensemble mean of the 54 AMIP runs from the reanalysis or observational products. Admittedly, the multimodel ensemble mean responses to SST forcing may be biased compared to observations, because models are not perfect. This might be the main limitation of the first approach. To consider the possible bias in the mean SST-forced component, we can perform linear regression of the time series of observations onto the SST-forced component (ensemble mean of the 54 AMIP runs) at each grid point. The residual after subtracting the regressed SST-forced component from the observations can be used to estimate the internally generated variations (Dai et al. 2015). The result from this method of analysis is comparable to our result obtained simply using the ensemble mean as the SSTforced component, since we focus on year-to-year variability, which is not significantly influenced by the magnitude of the model mean bias. To reduce the model biases in simulating the year-to-year evolution in response to SST forcing, we use as many members as possible (54 total) for calculating the ensemble mean. The second approach uses an SSTClim run in which the AGCM is forced by the monthly varying climatological seasonal cycle of SST and sea ice as its lower boundary condition. Because of the absence of SST variability beyond the mean seasonal cycle, year-to-year atmospheric fluctuations in the simulations can only be attributed to internal atmospheric dynamics. These two methods have been widely used in previous studies to distinguish the relative roles of SST forcing and internal atmospheric variability (e.g., Teng et al. 2013; Dai et al. 2015; Steinman et al. 2015; Song and Zhou 2015; Chen and Zhou 2017; He et al. 2017). Both methods are used in this study to establish the robustness of our results. It must be clarified that the internal atmospheric variability here also includes the part due to land surface anomalies such as soil moisture, which has been demonstrated to feed back significantly to the atmospheric circulation through land-atmosphere coupling (Koster et al. 2014, 2016). Thus, the so-called internal atmospheric variability here is not purely internal to the atmosphere, but refers to the part of variability independent of the SST/sea ice forcing, which is prescribed in the AMIP simulations.

Several indices are used to describe atmospheric circulation. Based on Chen et al. (2018), the Pacific-North American teleconnection (PNA) is defined as the first empirical orthogonal function (EOF) mode of the $500-\mathrm{hPa}$ GPH over the North Pacific $\left(0^{\circ}-90^{\circ} \mathrm{N}, 120^{\circ} \mathrm{E}-60^{\circ} \mathrm{W}\right)$.
The North Pacific Oscillation (NPO) is defined as the second EOF mode of SLP over the North Pacific $\left(0^{\circ}-\right.$ $\left.90^{\circ} \mathrm{N}, 120^{\circ} \mathrm{E}-60^{\circ} \mathrm{W}\right)$. The circumglobal pattern is a quasistationary large-scale atmospheric Rossby wave that originates from midlatitude atmospheric internal dynamics (Branstator 2002; Teng et al. 2013; Teng and Branstator 2017). Hence, we define a circumglobal pattern index in section $3 \mathrm{c}$ by projecting the GPH anomalies onto the circumglobal wave pattern over the midlatitudes (Fig. 9b).

\section{Results}

\section{a. Dominant modes of extreme precipitation}

To understand precipitation during boreal winter, we first analyze the climatological daily precipitation (Fig. 1a), extreme precipitation (95th percentile) threshold (Fig. 1b), total extreme precipitation (Fig. 1c), and total nonextreme precipitation (Fig. 1d) in DJF. Each variable displays similar spatial patterns featuring a maximum band along the west coast of North America. The total precipitation amount in winter includes contributions of $20 \%-60 \%$ from extreme precipitation, consistent with Lamjiri et al. (2017), and 80\%-40\% from nonextreme precipitation along the west coast of North America from north to south (Figs. 1e,f). To choose an area within which precipitation varies in the same phase for spatial averaging, EOF analysis is conducted on the monthly extreme, nonextreme, and mean precipitation for the yearly DJF mean (Fig. 2). The leading mode of variances in winter extreme precipitation displays a north-south dipole pattern along the entire west coast of North America (Fig. 2a), which dominates the spatial pattern of mean precipitation variability (Fig. 2e), while nonextreme precipitation features same-signed signals along the North American coast (Fig. 2c). Note that the dipole pattern we identified based on accumulated winter precipitation is broader than the dipole pattern revealed by previous studies (e.g., Neiman et al. 2008; Warner et al. 2012) focusing on the synoptic features of individual precipitation events. Choosing a smaller region over $35^{\circ}-60^{\circ} \mathrm{N}, 120^{\circ}-140^{\circ} \mathrm{W}$ for EOF analysis does not affect our results (not shown). For further analysis, we select the southern lobe of the north-south dipole pattern with in-phase variance of extreme and nonextreme precipitation over the U.S. West Coast $\left(35^{\circ}-\right.$ $50^{\circ} \mathrm{N}, 130^{\circ}-118^{\circ} \mathrm{W}$ ) as our analysis region, which follows the evolution of the first principal component (PC1). For the areal mean of the U.S. West Coast, both extreme and nonextreme precipitation show consistent variations with the mean precipitation, with correlation coefficients reaching 0.87 and 0.92 , respectively, which are statistically significant at the $99 \%$ level of confidence. In addition, the correlation between extreme and 
(a) extreme EOF1

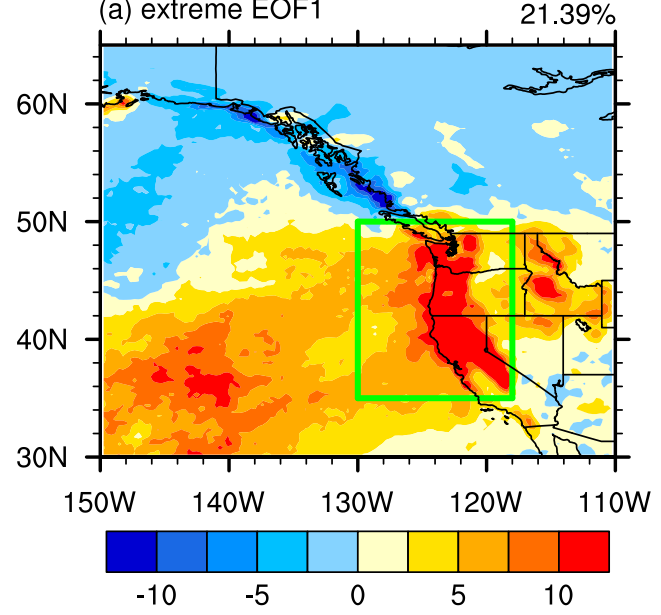

(c) non-extreme EOF1

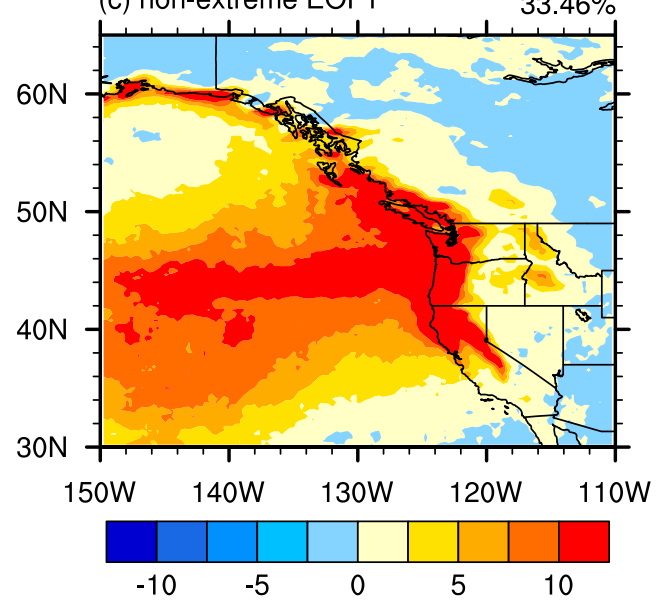

(e) mean EOF1

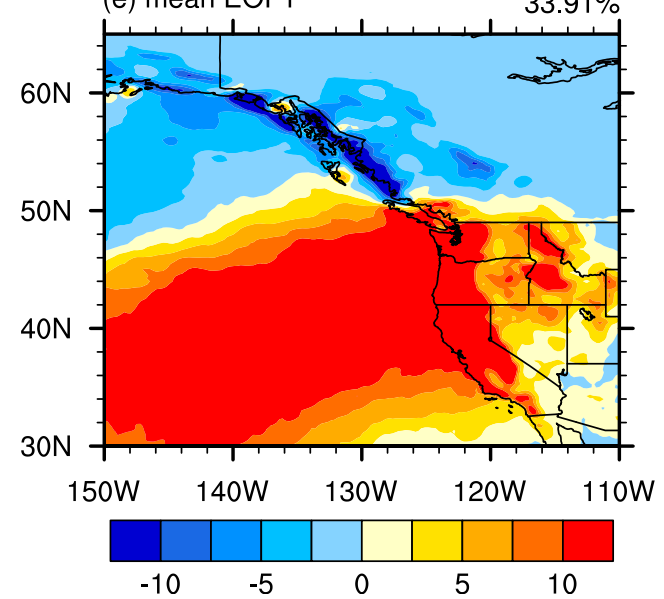

(b) extreme Prec

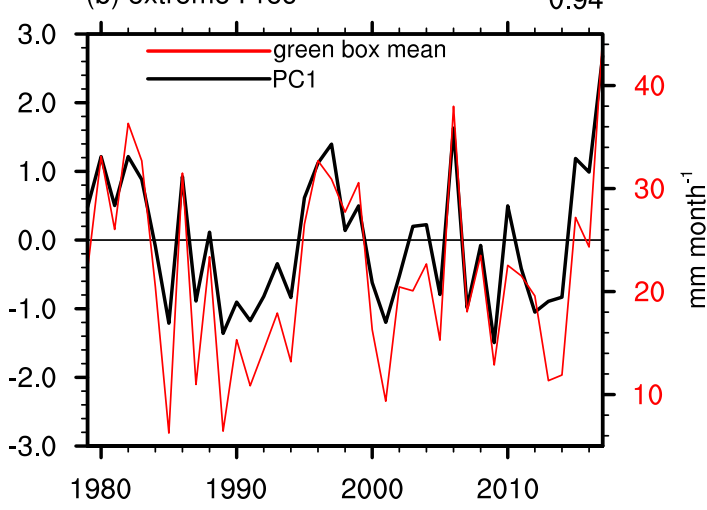

(d) non-extreme Prec

0.85

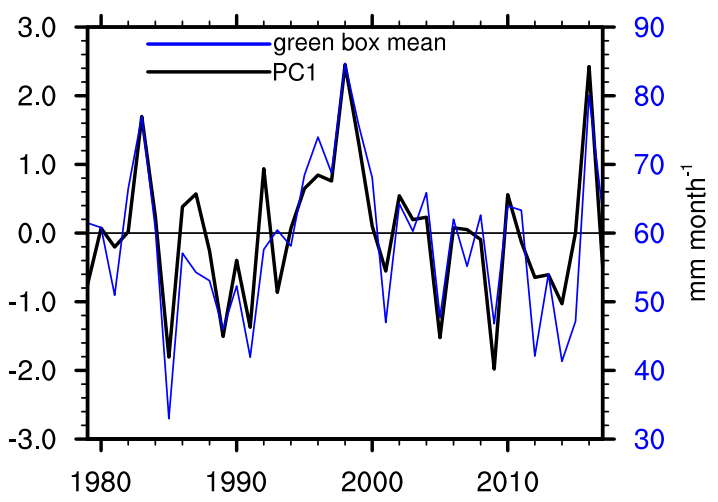

(f) mean Prec

0.94

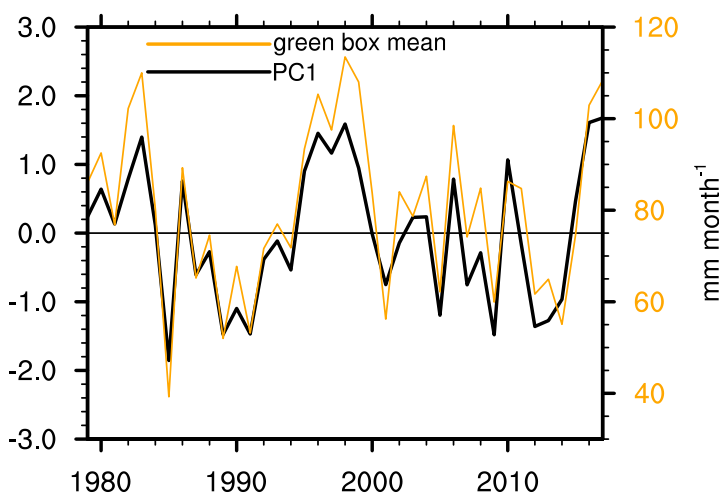

FIG. 2. (left) The leading EOF pattern (mm month ${ }^{-1}$ ) and (right) associated standardized PC (black lines corresponding to the left $y$ axis) of (a),(b) monthly extreme precipitation; (c),(d) monthly nonextreme precipitation; (e),(f) monthly mean precipitation averaged in DJF during 1979-2017. The red, blue, and orange lines in (b), (d), and (f) indicate the area mean of the U.S. West Coast [green box in (a)] for extreme, nonextreme, and mean precipitation ( $\mathrm{mm}$ month ${ }^{-1}$ corresponding to the right $y$ axis). The linear trend of 1979-2017 has been removed. The values given on the top right of the left panels represent the percentage variance explained by each mode, and the values on the right panels represent the correlation coefficients between the black and colored lines. 
(a) Climatology ARs in DJF

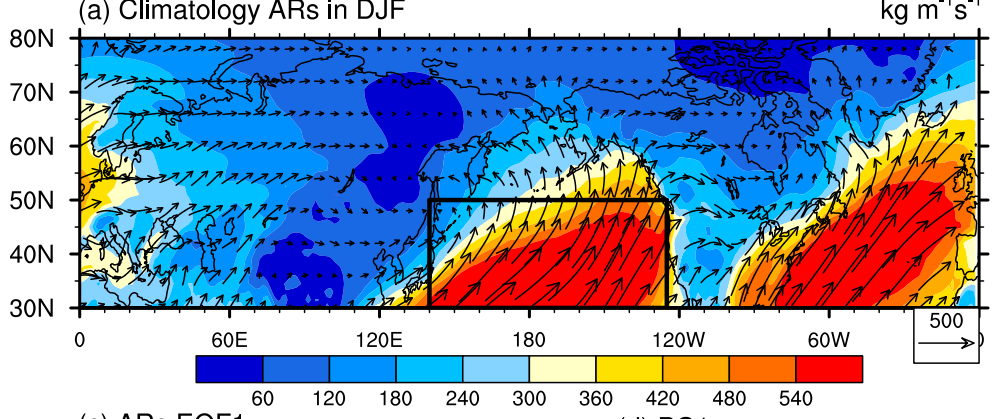

(b) STD in DJF

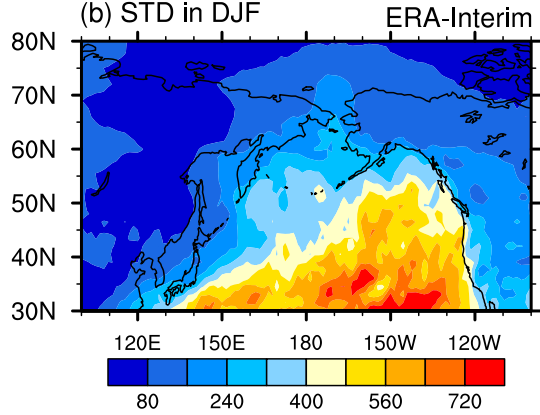

(c) ARs EOF1 $23.13 \%$
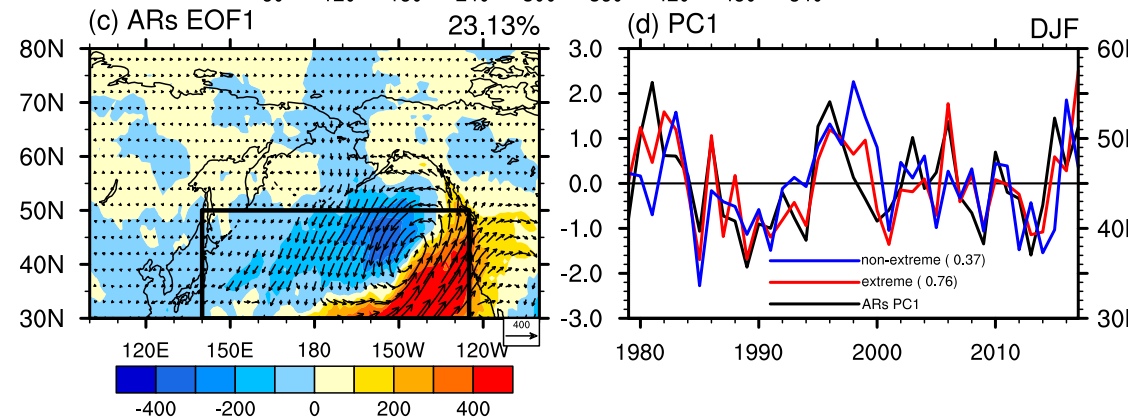

(e) extreme Prec
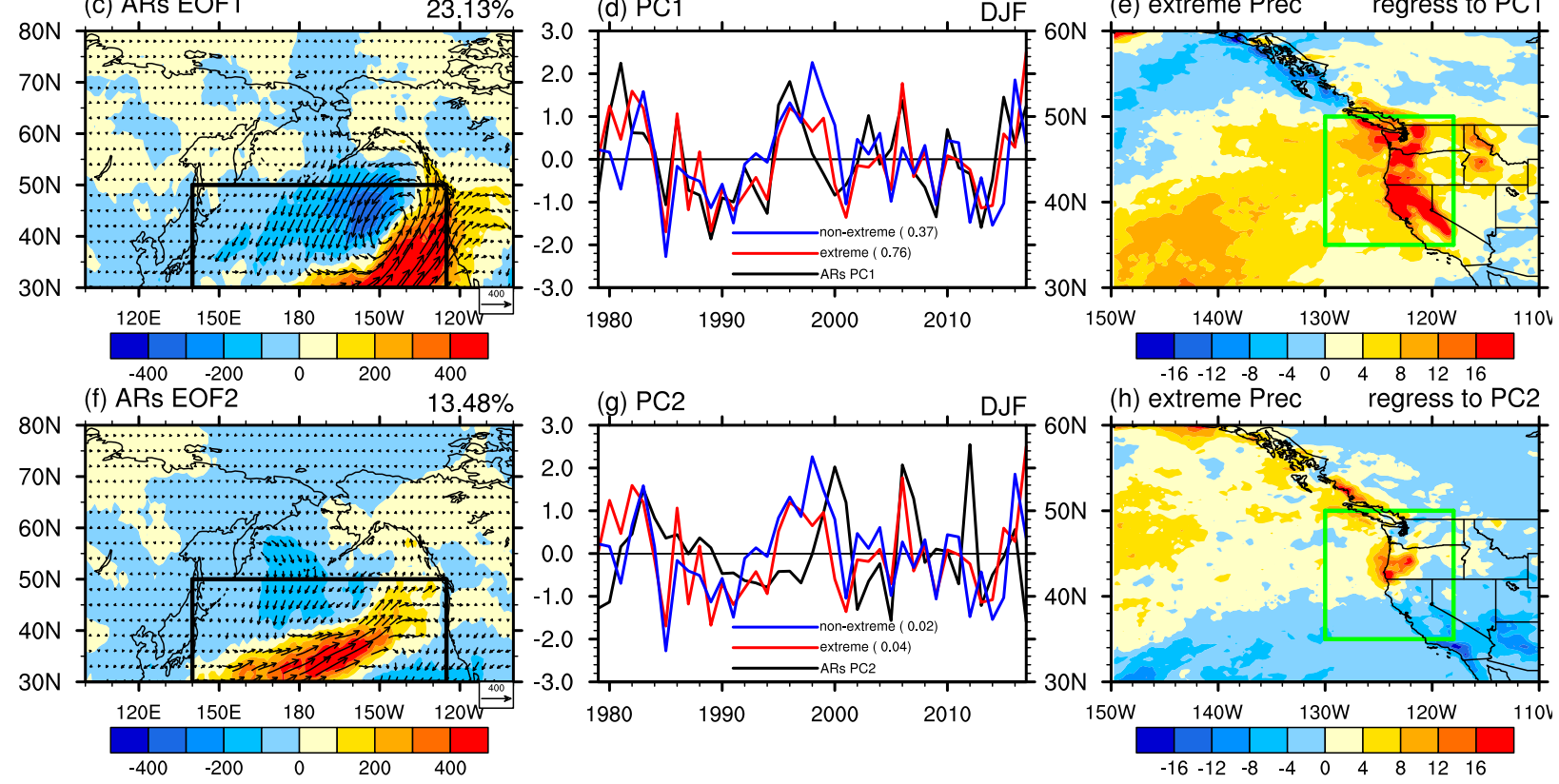

(h) extreme Prec

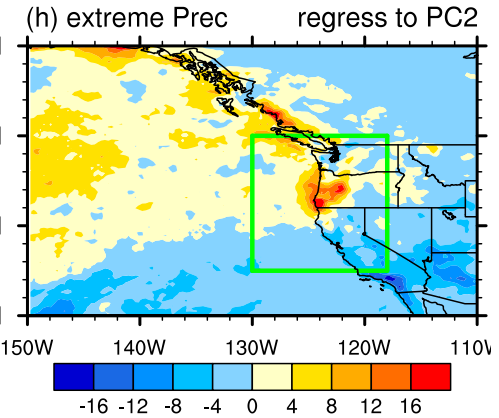

FIG. 3. (a) Climatology of daily IVT $\left(\mathrm{kg} \mathrm{m}^{-1} \mathrm{~s}^{-1}\right)$ by ARs ( $>95$ th percentile daily IVT). (b) Standard deviations $\left(\mathrm{kg} \mathrm{m}^{-1} \mathrm{~s}^{-1}\right)$ of IVT by ARs. The (c),(d) first and (f),(g) second dominant EOF patterns $\left(\mathrm{kg} \mathrm{m}^{-1} \mathrm{~s}^{-1}\right)$ and standardized PCs (black lines) of IVT by ARs. The red and blue lines in (d) and (g) are standardized time series of extreme and nonextreme precipitation along the U.S. West Coast, respectively, averaged over the green box, and their correlation coefficients with each PC are shown in parentheses. Regression patterns of extreme precipitation (mm month ${ }^{-1}$ ) onto (e) PC1 and (h) PC2. IVT inside the black box is used for the EOF analysis. The values given on the top right of (c) and (f) represent the percentage variance explained by each mode. ARs are based on ERA-Interim, and extreme precipitation is from NARR. All results are determined from the historical period of 1979-2017 during DJF.

nonextreme precipitation (red and blue lines in Figs. $2 \mathrm{~b}$ and $2 \mathrm{~d}$ ) is 0.62 for $1979-2017$. The time evolution of the extreme and nonextreme precipitation indicates their tendency to covary in strong El Niño years such as 1982/ 83 and 1997/98, but they differ in other years such as the winters of 2005/06 and 2016/17.

To explore the effect of the North Pacific ARs on extreme precipitation along the U.S. West Coast in DJF, the dominant modes of AR variations along with the climatology of ARs are shown in Fig. 3. Only the IVT associated with ARs ( $>95$ th percentile of daily IVT) for each grid cell are chosen and included in Fig. 3. Consistent with previous climatological studies (e.g., Ralph et al. 2006; Leung and Qian 2009; Neiman et al. 2011), ARs transport large amounts $\left(423.6 \mathrm{~kg} \mathrm{~m}^{-1} \mathrm{~s}^{-1}\right)$ of water vapor climatologically from the North Pacific to the mid- to high latitudes and the U.S. West Coast, compared to the climatological average daily IVT of $140.2 \mathrm{~kg} \mathrm{~m}^{-1} \mathrm{~s}^{-1}$ over the North Pacific (black box in Fig. 3a). Areas of large DJF variability in AR IVT are located at the southern portion of the ARs that coincide with the latitude of the U.S. West Coast (Fig. 3b), consistent with Warner and Mass (2017). Climate models project equatorward shifts in ARs under global warming that may further increase the variability of IVT south of the ARs (Payne and Magnusdottir 2015; Shields and Kiehl 2016). These suggest that the IVT variability in the subtropical Pacific Ocean may play an important role in modulating precipitation variability along the U.S. West Coast. 

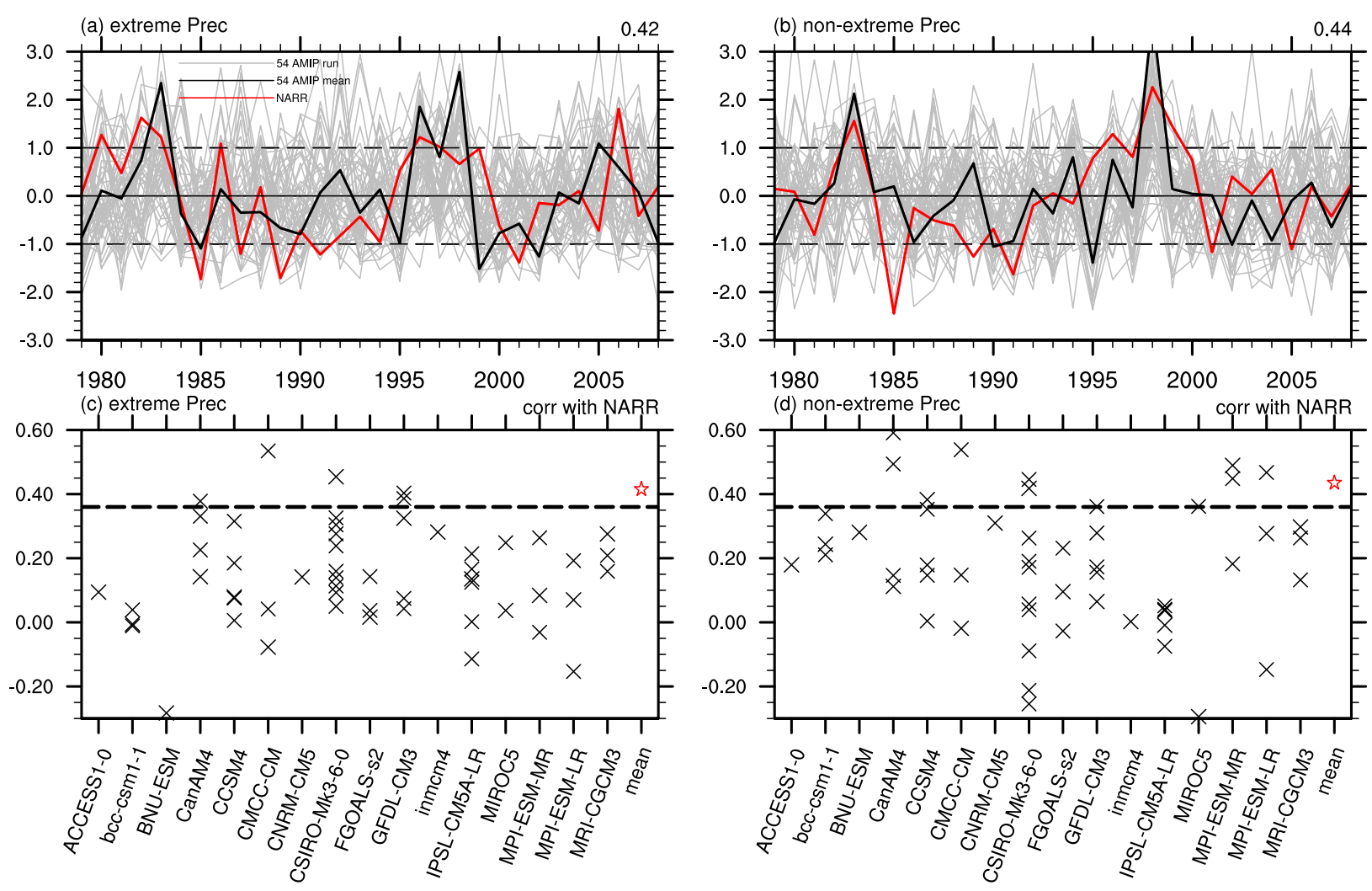

FIG. 4. (top) Time series of standardized DJF-averaged (a) extreme and (b) nonextreme precipitation along the U.S. West Coast based on NARR (red), 54 AMIP runs (gray), and their ensemble mean (black). The values given on the top right of (a) and (b) represent the correlation coefficients between the black and red lines. (bottom) Correlation coefficients between NARR and simulated (c) extreme and (d) nonextreme precipitation from each AMIP run during 1979-2008 (crosses). The dashed line indicates correlation coefficients that are statistically significant at the $95 \%$ level of confidence. The skill of the ensemble mean is marked by the red star.

Like that of the leading mode of extreme precipitation variability, the first EOF mode of IVT associated with ARs is characterized by a north-south dipole pattern with anomalous anticyclonic or cyclonic circulation over the North Pacific (Fig. 3c), indicating a northsouth shift of ARs. The significant impact of this EOF mode of ARs on the extreme precipitation over the West Coast (Fig. 3e) is evidenced by their correlation coefficient at 0.76 (Fig. 3d), which is statistically significant at the $99 \%$ level of confidence. Furthermore, the first PC of extreme precipitation (Fig. 2b) is also significantly correlated with the first PC of ARs (Fig. 3d), with the correlation coefficient reaching 0.79 . Therefore, the north-south shift of ARs over the North Pacific is closely related to the north-south dipole mode of extreme precipitation along the West Coast. The second EOF mode features variations in IVT associated with the main stretch of the ARs located far from the coast of North America. This EOF mode is associated with ARs that do not make landfall and is therefore not correlated with the precipitation along the U.S. West Coast (Figs. 3f-h).

\section{b. SST forcing}

We use the ensemble mean of 54 AMIP simulations from 16 CMIP5 models (Table 1) to estimate the SST-forced variability. The correlation coefficients between the observed and simulated ensemble mean precipitation are 0.42 and 0.44 during 1979-2008 for extreme and nonextreme precipitation, respectively (Fig. 4). Both are statistically significant at the $95 \%$ level of confidence. This indicates that SST forcing can significantly regulate precipitation variability along the U.S. West Coast. Approximately $18 \%$ $(19 \%)$ of the variances of winter extreme (nonextreme) precipitation during 1979-2008 can be explained by SST forcing, while the residual can be attributed to internal atmospheric variability. In addition, the ensemble mean of 54 AMIP runs shows higher correlation with observations than most of the individual members (Figs. 4c,d), confirming that the ensemble mean can largely suppress the internal atmospheric noise and highlight the SST-forced component.

The large-scale environment in favor of extreme precipitation along the U.S. West Coast in winter under SST forcing is shown in Fig. 5. Results from both HadISST and ERSST.v4 show that an El Niño-like SST 
pattern with warm anomalies in the tropical central-toeastern Pacific and cold anomalies in the North Pacific increases extreme precipitation along the U.S. West Coast (Figs. 5a,b). Evidently, warm SST anomalies in the tropical Pacific induce a PNA atmospheric teleconnection with a barotropic cyclonic circulation covering most of the North Pacific (Figs. 5e-h). Along the southern flank of the cyclonic circulation, water vapor over the warm ocean is advected by the southwesterly flow of the ARs that influence the U.S. West Coast (Figs. 5c,d). Notably, a consistent conclusion is obtained from both the ERA-Interim and NCEP1 reanalysis products.

To further explore the large-scale environment favoring extreme precipitation, the circulation anomalies in favor of nonextreme precipitation under SST forcing are shown in Fig. 6. Compared to extreme precipitation, warm SST anomalies confined to the far eastern tropical Pacific along with cold SST anomalies over the North Pacific promote more nonextreme precipitation along the U.S. West Coast. A small cyclonic circulation over the eastern North Pacific transports more water vapor to the coast, inducing more precipitation there. However, the anomalous water vapor transport is from higher latitudes over the colder ocean and weaker than that associated with extreme precipitation; hence, it is not strong enough to be qualified as an AR, which requires IVT to be greater than the 95th percentile value. Thus, nonextreme precipitation over the West Coast is generally not associated with ARs and does not show significant correlation with the PCs of the ARs (blue lines in Figs. $3 \mathrm{~d}$ and $3 \mathrm{~g}$ ).

PNA and NPO are two important patterns of atmospheric teleconnection in the Northern Hemisphere, with prominent centers of action over the North Pacific basin (Chen et al. 2018). The large cyclonic circulation over most of the North Pacific associated with extreme precipitation (Figs. $5 \mathrm{~g}, \mathrm{~h}$ ) is recognizably the PNA pattern, while the small cyclonic circulation over the eastern North Pacific and West Coast associated with nonextreme precipitation (Figs. 6e,f) resembles the pattern of NPO. Thus, we hypothesize that SST forcing influences extreme and nonextreme precipitation through the PNA and NPO teleconnections, respectively. To test this hypothesis, time series and spatial patterns of PNA and NPO under SST forcing are compared with the extreme and nonextreme precipitation (Fig. 7). SST-forced extreme precipitation is highly correlated with PNA (0.71), and nonextreme precipitation is well related to NPO (0.77), both statistically significant at the $99 \%$ level of confidence. In addition, the spatial patterns in Figs. $5 \mathrm{~g}$ and $5 \mathrm{~h}$ resemble the PNA pattern, with pattern correlation coefficients of 0.84 (ERA-Interim) and 0.85 (NCEP1), respectively, in the domain used to define PNA $\left(0^{\circ}-\right.$ $\left.90^{\circ} \mathrm{N}, 120^{\circ} \mathrm{E}-60^{\circ} \mathrm{W}\right)$. The spatial patterns of SLP in Figs. $6 \mathrm{e}$ and $6 \mathrm{f}$ resemble the NPO pattern, with pattern correlation coefficients of 0.67 (ERA-Interim) and 0.66 (NCEP1), both statistically significant at $99 \%$ level of confidence. Therefore, we can conclude that SSTforced extreme precipitation is highly correlated with the PNA, while the nonextreme precipitation is more correlated with NPO. Further, the SST patterns related to PNA and NPO (Figs. 7e,f) bear marked resemblance to those driving the extreme (Figs. 5a,b) and nonextreme (Figs. 6a,b) precipitation, respectively. We infer that it is the SST anomalies in the tropical central-to-eastern Pacific that drive a PNAlike teleconnection pattern, which organizes ARs in a way to bring more precipitation extremes to the U.S. West Coast, while NPO is more sensitive to the SST anomalies in the far eastern tropical Pacific. This assertion is further supported by the fact that both PNA and extreme precipitation are significantly correlated with SST anomalies over the Niño-3.4 $\left(5^{\circ} \mathrm{N}-5^{\circ} \mathrm{S}, 170^{\circ}-\right.$ $120^{\circ} \mathrm{W}$; correlation coefficients of 0.92 and 0.56 , respectively) and Niño- $1+2\left(0^{\circ}-10^{\circ} \mathrm{S}, 90^{\circ}-80^{\circ} \mathrm{W} ; 0.73\right.$ and 0.60) regions, while the NPO and nonextreme precipitation are only well correlated with the Niño$1+2$ region $(0.51$ and 0.63$)$, but not the Niño-3.4 region (0.05 and 0.28$)$. The regions chosen for calculating the Niño indices are based on https://www.esrl.noaa.gov/ psd/data/climateindices/list/.

\section{c. Internal atmospheric variability}

Although SST has statistically significant impacts on extreme and nonextreme precipitation along the U.S. West Coast, Fig. 4 suggests that the DJF precipitation variability is associated primarily with internal atmospheric dynamics. The relationship between extreme precipitation and intrinsic atmospheric dynamics has not been studied as extensively as the SST-forced counterpart. After subtracting the SST-forced component from the observation, the internal atmospheric component of extreme precipitation is well correlated with the observation, with a correlation coefficient of 0.90 (Fig. 8a). This indicates that $81 \%$ of variances in winter extreme precipitation can be attributed to internal atmospheric variability independent of SST forcing. Over the mid- to high latitudes, a wave packet propagated from Eurasia to the Pacific manifests as a wave train of amplified ridges and troughs in the eastern Pacific along the U.S. West Coast (Figs. 8f-i). The wave structure shows a hemisphere-wide pattern and is trapped within the latitudes of the westerly jets. The wave pattern exhibits a marked resemblance with the circumglobal 
SST forced extreme precipitation
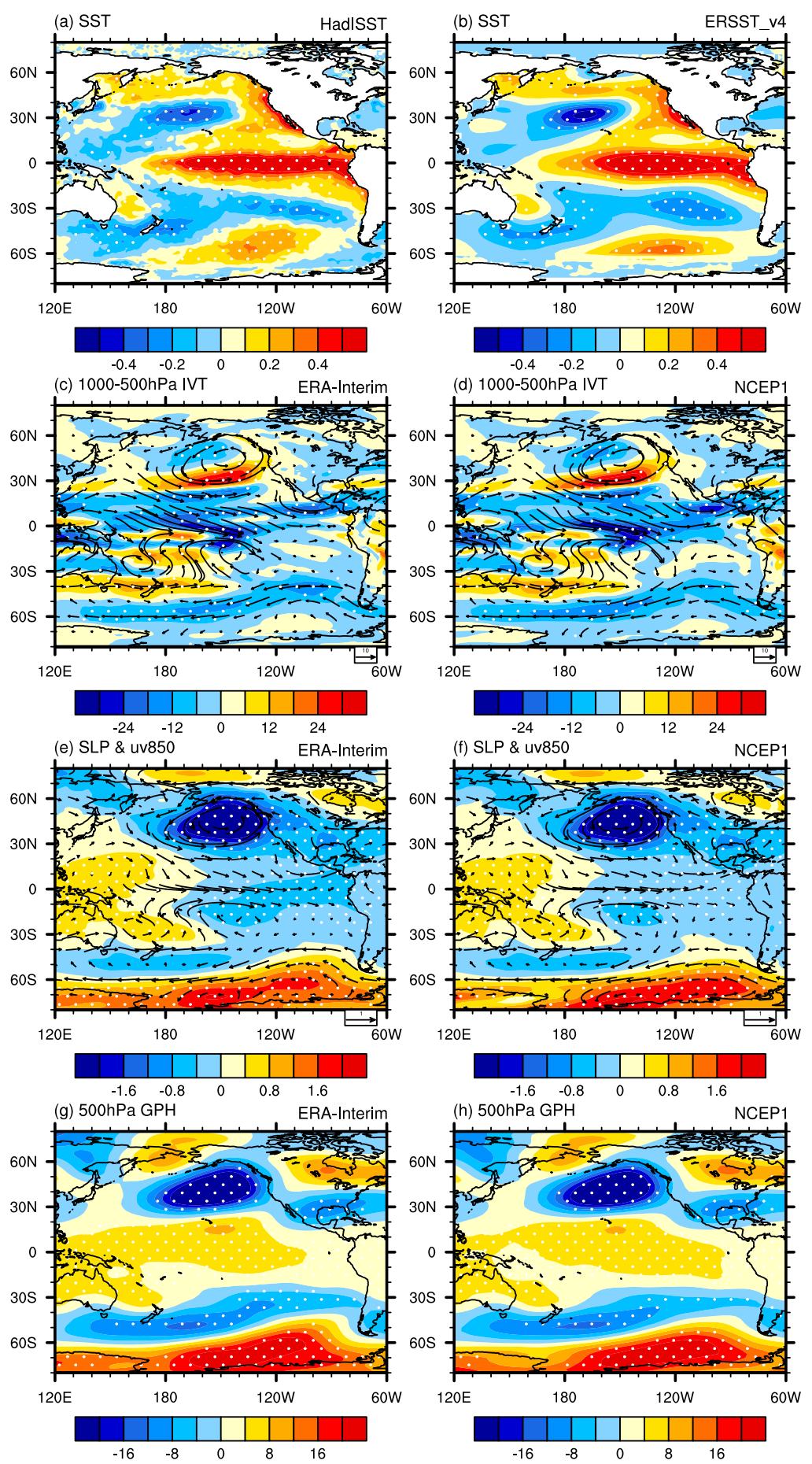

FIG. 5. Regression patterns of monthly SST $\left({ }^{\circ} \mathrm{C}\right)$ from (a) HadISST and (b) ERSST. v4; (c),(d) IVT vector and magnitude integrated over 1000-500 $\mathrm{hPa}\left(\mathrm{kg} \mathrm{m}^{-1} \mathrm{~s}^{-1}\right)$, (e),(f) SLP (hPa) and wind vector at $850 \mathrm{hPa}\left(\mathrm{m} \mathrm{s}^{-1}\right)$, and (g),(h) $\mathrm{GPH}$ at $500 \mathrm{hPa}$ (m) averaged in DJF during 1979-2008 onto the time series of extreme precipitation forced by SST shown as the black line in Fig. 4a. Variables of (c), (e), and (g) are from ERA-Interim, and (d), (f), and (h) are from NCEP1. The dotted areas indicate that the regression coefficients are statistically significant at the $90 \%$ level of confidence. 


\section{SST forced non-extreme precipitation}
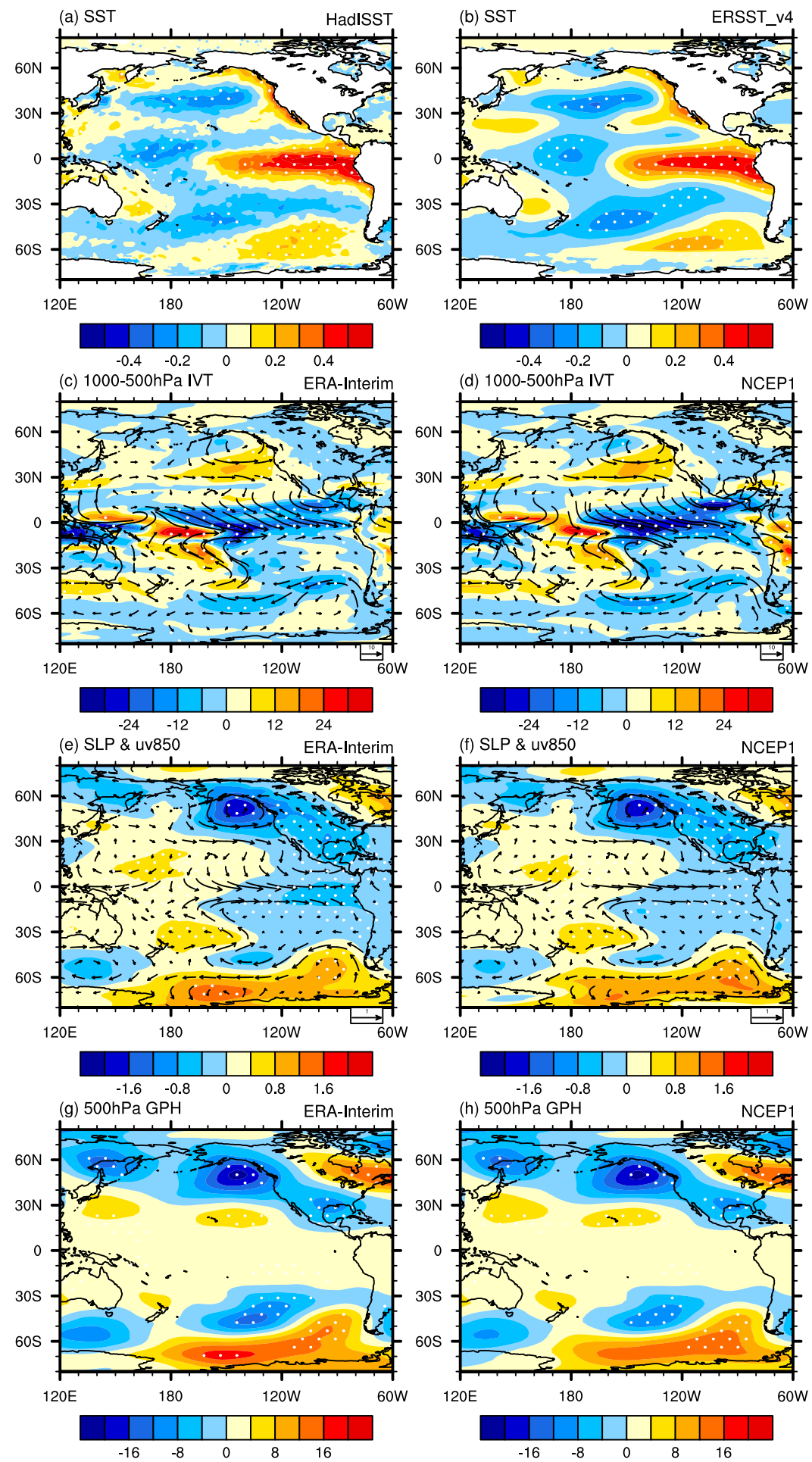

FIG. 6. As in Fig. 5, but for the regression patterns onto the time series of nonextreme precipitation forced by SST shown as the black line in Fig. 4b. 

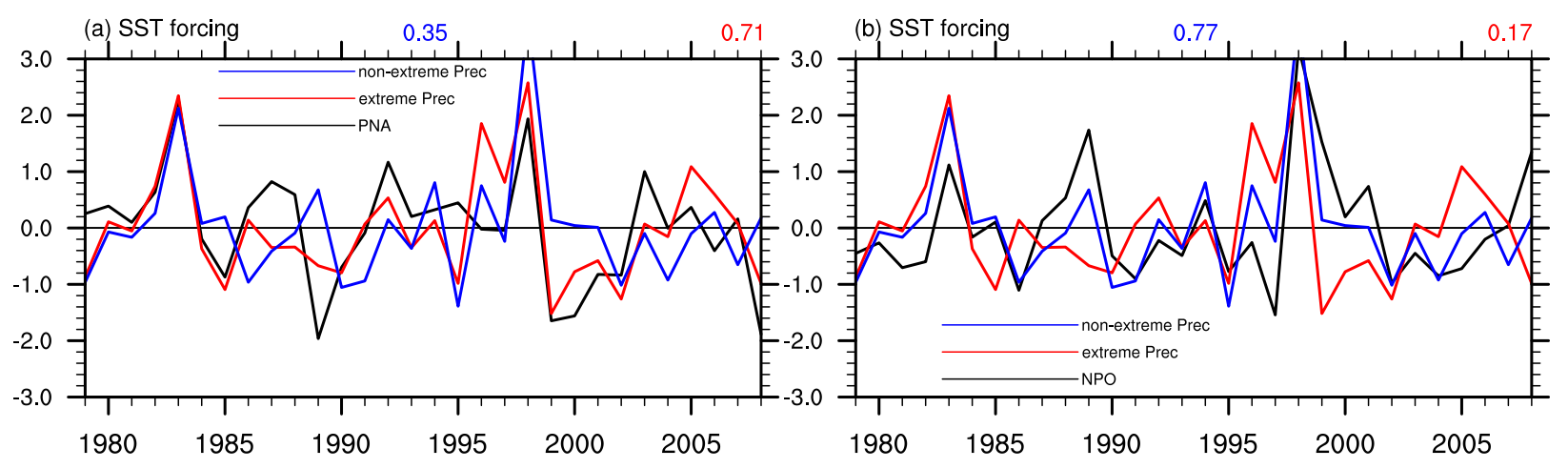

(c) SST forcing PNA

$64.91 \% \quad$ (d) SST forcing NPO
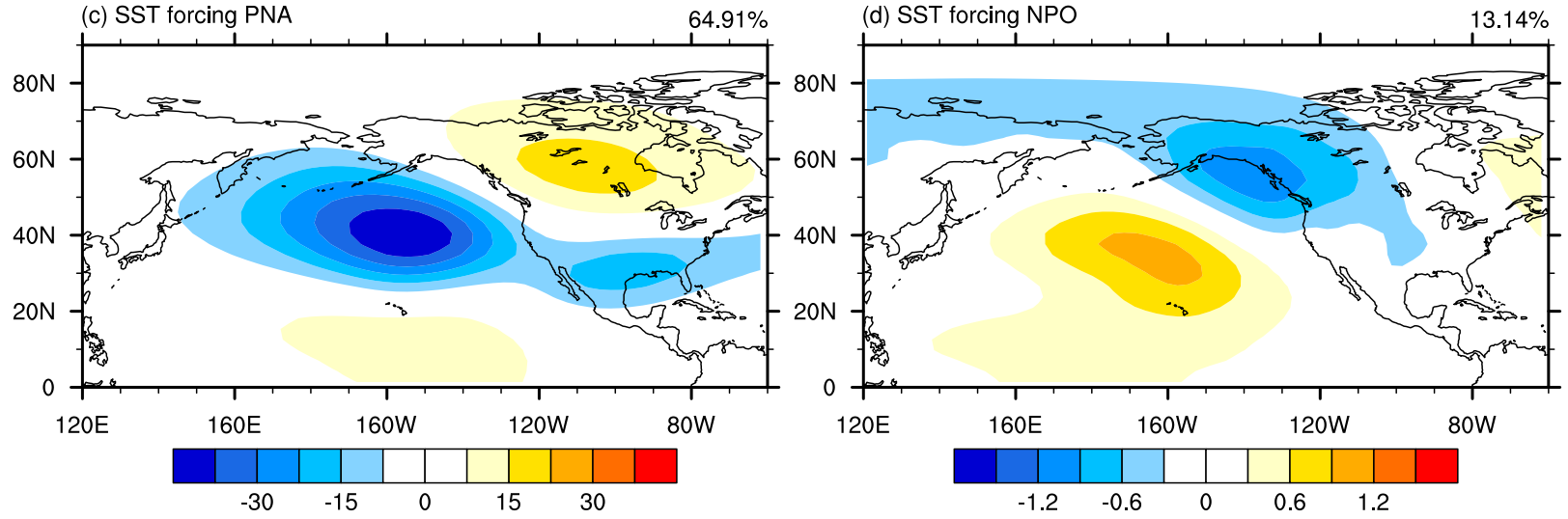

(e) PNA related SST

54 AMIP mean
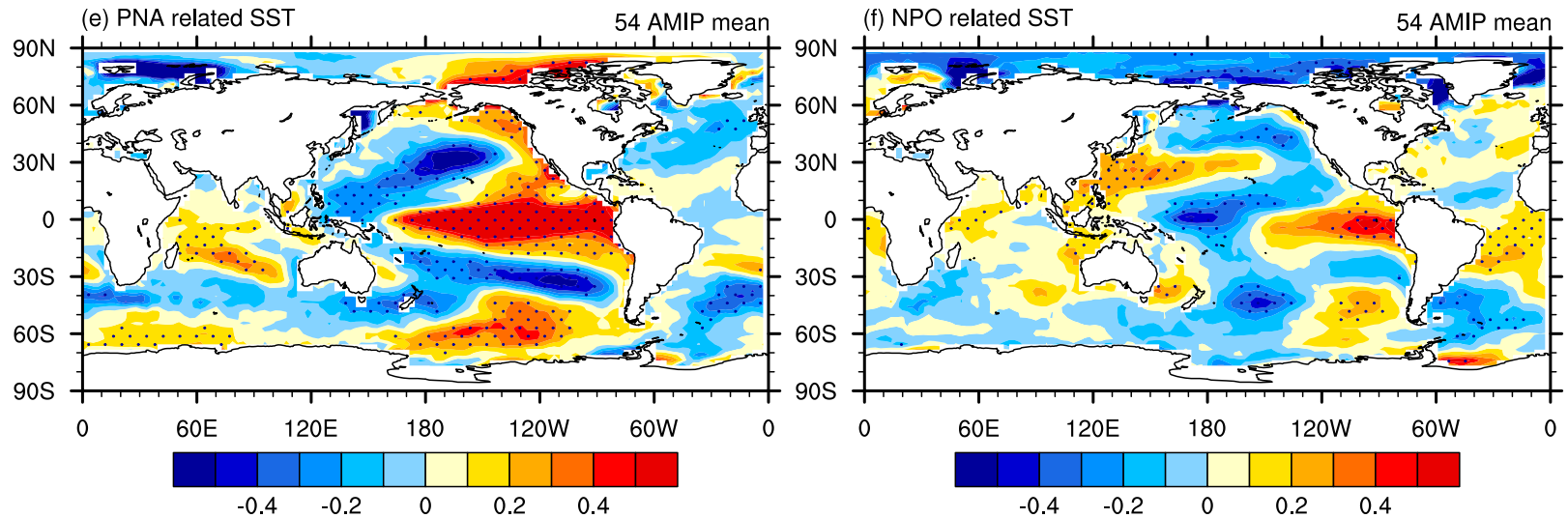

FIG. 7. Standardized time series (black) and spatial patterns of (a),(c) PNA (m) and (b),(d) NPO (hPa) under SST forcing, with percentage variance given on the top right of (c) and (d). Regression patterns of SST $\left({ }^{\circ} \mathrm{C}\right.$ ) onto (e) PNA and (f) NPO. The red and blue lines in (a) and (b) are time series of standardized extreme and nonextreme precipitation along the U.S West Coast under SST forcing. The values given on the top right (center) of (a) and (b) represent the correlation coefficients between extreme (nonextreme) precipitation with PNA in (a) and NPO in (b). All results are based on the ensemble mean of 54 AMIP runs listed in Table 1. The dotted areas in (e) and (f) indicate that the regression coefficients are statistically significant at the $95 \%$ level of confidence.

teleconnection, including that associated with the North Atlantic Oscillation-like feature in the EuroAtlantic sector (Fig. 2b in Branstator 2002). A cyclonic circulation over the U.S. West Coast enhances the water vapor transport by the ARs (Figs. 8d,e), favoring more extreme precipitation. It indicates that different sources of forcing that modulate the strength and location of the circumglobal teleconnection may influence the winter extreme precipitation and its variance.

The circumglobal wave train can arise naturally from the waveguide effect of the midlatitude jet stream (Branstator 2002) and is primarily a manifestation of the mid- to high-latitude intrinsic variability, but this does 

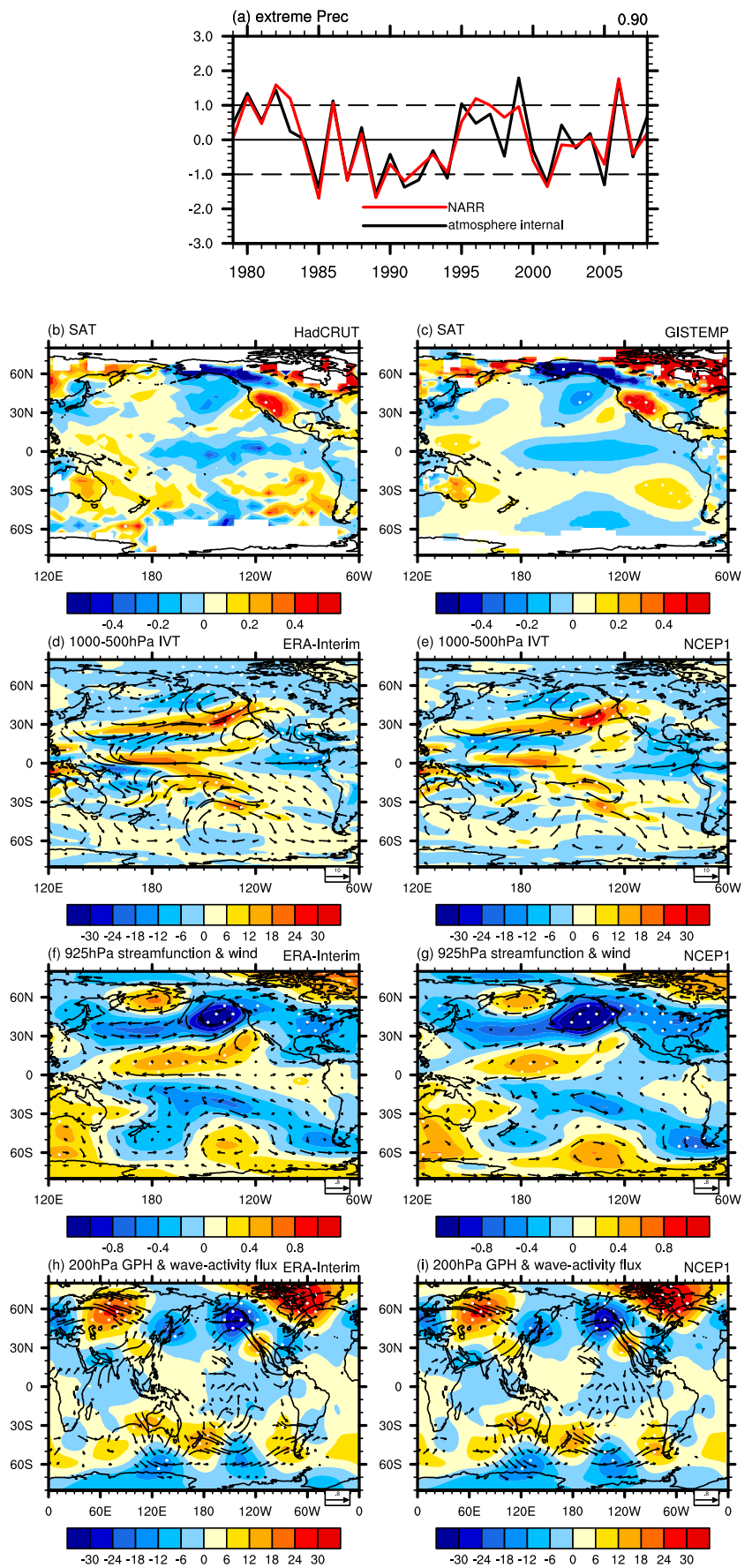

FIG. 8. (a) Standardized time series of extreme precipitation from NARR (red) and atmospheric internal variability (black) obtained by the difference between NARR and the ensemble mean of 54 AMIP runs. Regression of monthly SAT $\left({ }^{\circ} \mathrm{C}\right)$ from (b) HadCRUT and (c) GISTEMP, (d),(e) IVT $\left(\mathrm{kg} \mathrm{m}^{-1} \mathrm{~s}^{-1}\right)$ vector and magnitude integrated over 1000$500 \mathrm{hPa}$, (f), (g) streamfunction $\left(\times 10^{6} \mathrm{~m}^{2} \mathrm{~s}^{-1}\right)$ and wind vector at $925 \mathrm{hPa}\left(\mathrm{m} \mathrm{s}^{-1}\right)$, and (h),(i) GPH (m) and wave-activity flux $\left(\mathrm{m}^{2} \mathrm{~s}^{-2}\right)$ at $200 \mathrm{hPa}$ averaged in DJF during 1979-2008 onto the time series of extreme precipitation under internal atmospheric variability shown as the black line in (a). Variables of (d), (f), and (h) are from ERA-Interim, and (e), (g), and (i) are from NCEP1. Note that the component correlated with SST forcing has been removed by linear regression before calculating the regression in (b)-(i). The dotted areas indicate that the regression coefficients are statistically significant at the $90 \%$ level of confidence. 
(a) NOAA internal OLR

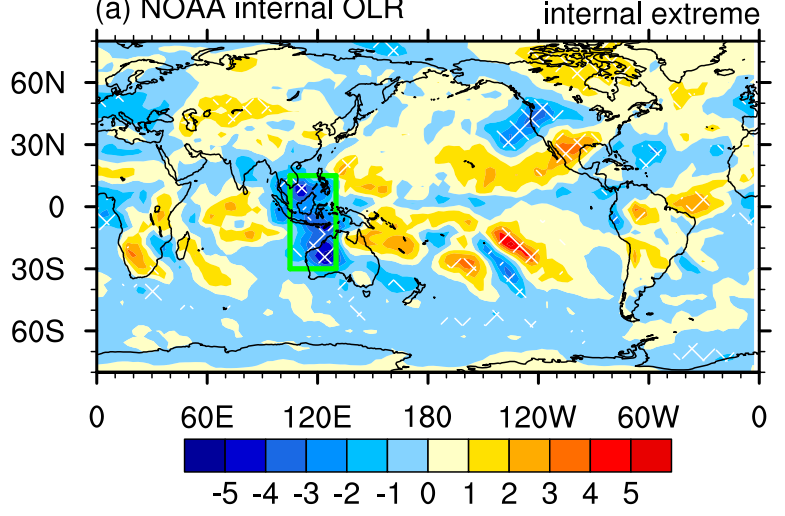

(c) Internal Atm

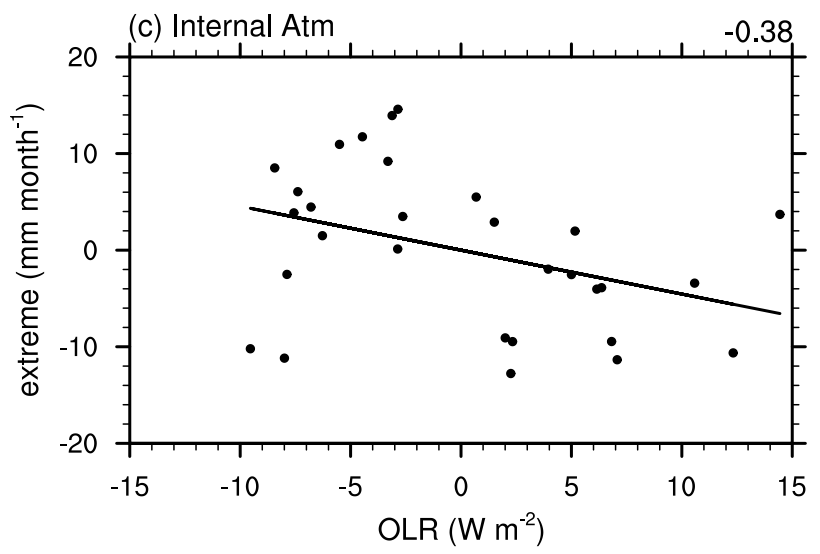

(b) ERA internal 500GPH

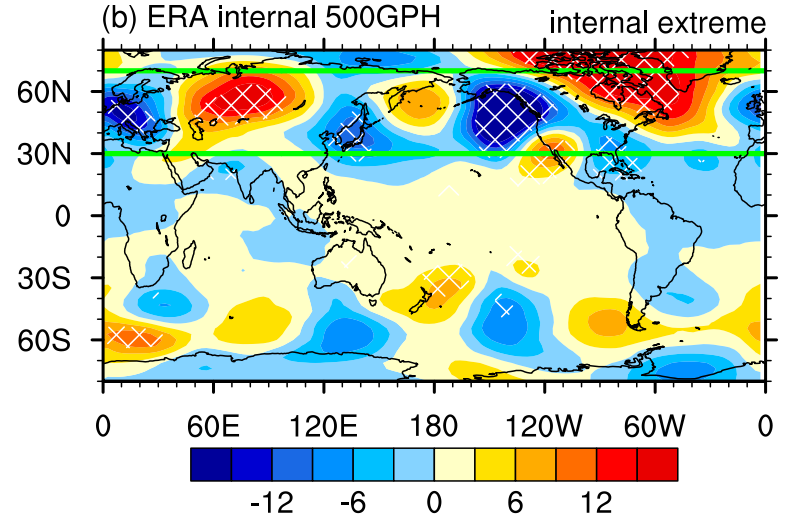

(d) Internal Atm

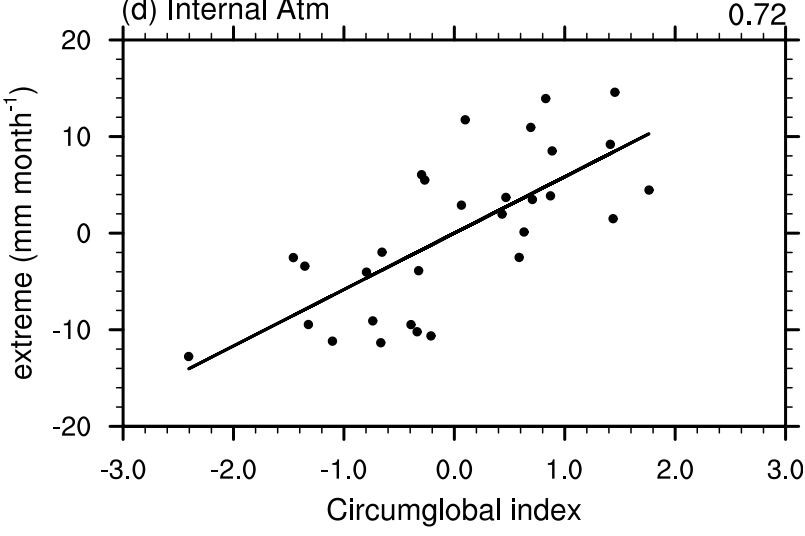

FIG. 9. Regression of monthly (a) OLR $\left(\mathrm{W} \mathrm{m}^{-2}\right.$ ) from NOAA and (b) GPH (m) at $500 \mathrm{hPa}$ from ERA-Interim in DJF onto the time series of extreme precipitation under internal atmospheric variability during 1979-2008 as shown by the black line in Fig. 8a. Scatterplot between extreme precipitation of NARR and (c) anomalies of OLR averaged over $30^{\circ} \mathrm{S}-15^{\circ} \mathrm{N}, 105^{\circ}-130^{\circ} \mathrm{E}$ [green box in (a)] and (d) circumglobal index defined as regression coefficients of GPH at $500 \mathrm{hPa}$ onto the pattern in (b) between $30^{\circ}$ and $70^{\circ} \mathrm{N}$ under internal atmospheric variability. Note that SST-forced signals based on the ensemble mean of 54 AMIP runs have been removed from the reanalysis datasets to obtain the internal atmospheric variations. The values given on the top right of (c) and (d) represent the correlation coefficients between the two variables. The crossed areas indicate that the regression coefficients are statistically significant at the $90 \%$ level of confidence.

not rule out the possibility of a tropical wave source exciting this wave pattern. Forcing associated with latent heating over the tropical western Pacific has been found to be especially adept at exciting the wave train (Teng and Branstator 2017). To clarify the tropical-extratropical interaction, we look into wave-activity flux at the $200-\mathrm{hPa}$ level. Wave-activity flux analysis (Kosaka and Nakamura 2006) suggests that there are two pathways for a wave train to propagate to the U.S. West Coast, the one through the mid- to high-latitude Eurasia continent, and the other from heating from the tropical western Pacific. Both can modulate the circumglobal pattern (Figs. 8h,i). The signals in the mid- to high latitudes and over the tropical western Pacific are present and consistent between ERA-Interim and NCEP1.

Here, the possible triggering of the circumglobal teleconnection from internal atmospheric dynamics is further explored. OLR is used as a proxy for tropical convection, with large negative OLR anomalies corresponding to enhanced convection. CMIP5 models can reproduce reasonably the magnitudes of observed OLR variances (not shown). With the SST-forced signals removed, a heating anomaly over the Maritime Continent (MC)-western Australian region is identified to be related to the extreme precipitation along the U.S. West Coast (Fig. 9a). The 500-hPa GPH is used for analyzing the wave train over the mid- to high latitudes. The significant circumglobal teleconnection associated with the extreme precipitation covers the mid- to high latitudes with cyclonic circulation over the U.S. West Coast (Fig. 9b). We define a circumglobal pattern index by projecting the internal GPH signal onto the circumglobal wave pattern over mid- to high latitudes, and find it significantly correlated with extreme precipitation at a coefficient of 0.72 , indicating that extreme precipitation in the U.S. West Coast is tightly related to the circumglobal 
teleconnection under internal atmospheric variability (Fig. 9d). Meanwhile, the OLR over the MC is found to be correlated with both the circumglobal index $(-0.47)$ and extreme precipitation $(-0.38)$ under internal atmospheric variability (Fig. 9c). Thus, it is conceivable that deep convection over the MC may influence extreme precipitation along the U.S. West Coast through the circumglobal wave pattern.

To further highlight the effect from internal atmospheric variability, an additional SSTClim experiment with the GFDL CM3 model forced by the monthly climatology of SST is examined. Since there is no year-to-year variation in SST forcing, the variances of extreme precipitation can only be attributed to internal atmospheric variability. As daily outputs are not available from the GFDL CM3 SSTClim run, we cannot obtain the extreme precipitation in the SSTClim run directly. Nevertheless, the large-scale environment related to extreme precipitation under internal atmospheric variability can be examined in this experiment, including the OLR anomalies over the MC and the circumglobal wave pattern over the mid- to high latitudes. The time series of OLR over the MC shows significant year-to-year variations (Fig. 10a), which is well related with water vapor transport by ARs (Fig. 10b), favoring the large-scale environment of extreme precipitation. The low-level streamfunction at $925 \mathrm{hPa}$ shows the wave train extending from the MC passing through East Asia and the Gulf of Alaska to the western United States (Fig. 10c), and the high-level GPH at $200 \mathrm{hPa}$ exhibits a great resemblance to the circumglobal pattern with the cyclonic circulation along the U.S. West Coast (Fig. 10d). Therefore, the SSTClim run supports the proposition that anomalous convection over the MC can excite the circumglobal wave pattern with a consequence of extreme precipitation over the U.S. West Coast, and this can occur as an internal variability of the atmosphere independent of SST forcing. In addition, the circumglobal index, obtained as the regression coefficient of $500-\mathrm{hPa}$ GPH onto the circumglobal wave pattern in Fig. 9b, also exhibits year-to-year variations (Fig. 10e) and is associated with more water vapor transport by ARs to the U.S. West Coast (Fig. 10f), favoring more extreme precipitation there. Thus, the SSTClim experiment confirms the relevance of the internal circumglobal wave pattern and its impact on extreme precipitation over the U.S. West Coast through modulating the pathways and intensity of ARs. The anomalous convection over the MC can also remotely influence the extreme precipitation over the western United States through this teleconnection mechanism.

\section{d. Winter of $2016 / 17$}

To explore whether the findings above derived from long-term historical records may help us to interpret specific extreme events, we now extend our analysis to the record extreme precipitation in California during the winter of 2016/17 that caused large economic losses. The winter of 2016/17 shows record extreme precipitation along the U.S. West Coast, with an above-normal number and intensity of ARs making landfall in California and close to record precipitation amounts reaching about 2.5 standard deviations above the U.S. West Coast area mean $\left(35^{\circ}-50^{\circ} \mathrm{N}, 130^{\circ}-118^{\circ} \mathrm{W}\right)$ for the historical period (1979-2017) (red line in Figs. 3d and 11a). However, nonextreme precipitation is normal, equivalent to roughly 0.36 of 1 standard deviation over the U.S. West Coast (blue line in Figs. 3d and 11b). The winter of 2016/17 is not an El Niño event, and the SST anomalies in the Pacific show no significant pattern correlation with those associated with extreme precipitation, with a pattern correlation of 0.06 (Figs. 11c and $5 a, b)$. On the other hand, a circumglobal wave train is evident over the mid- to high latitudes in both lowlevel and high-level tropospheric circulation, especially over the North Pacific, with a cyclonic circulation and an anomalous southwesterly wind over California (Figs. 11e,f), steering more frequent and stronger ARs toward making landfall there (Fig. 11d). Meanwhile, there is an enhanced convection over the MC-western Australian region (Fig. 11g), appearing to serve as the wave source for the wave train emanating from the MC and passing through East Asia and the Gulf of Alaska to the western United States (Figs. 11e,f). In view of the resemblance of these large-scale circulation features to the internal variability patterns associated with U.S. West Coast extreme precipitation identified from longterm historical records (Figs. 8, 9, and 10), we speculate that the record extreme precipitation over the U.S West Coast during the winter of 2016/17 may be mostly the result of internal atmospheric variability rather than SST forcing. It is understandable that the wave pattern in the winter of 2016/17 and that from the long-term historical records are not identical, as the latter reflects the common features of many extreme precipitation events but each event is expected to have some unique features. These results notwithstanding, more rigorous attribution for the causes of the extreme 2016/17 winter, especially the link between tropical convection and extreme precipitation, requires hypothesis-driven numerical experiments and further analysis.

\section{Conclusions and discussion}

This study explores the relative roles of SST forcing versus internal atmospheric variability in the year-toyear variation of winter (December-February) extreme precipitation along the U.S. West Coast. Analyses of 
(a) -OLR index

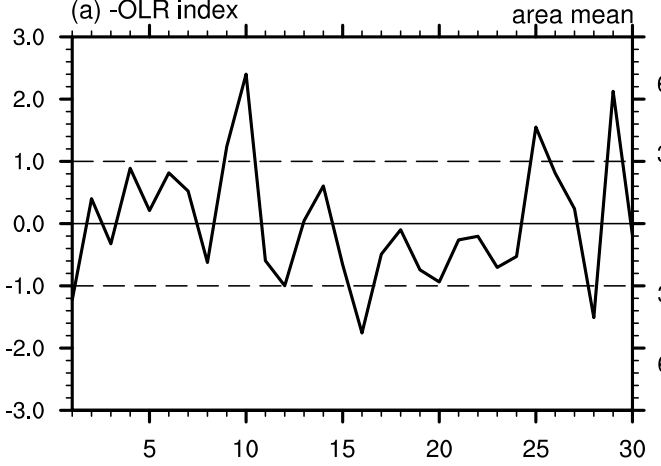

(b) $1000-500 \mathrm{hPa}$ IVT

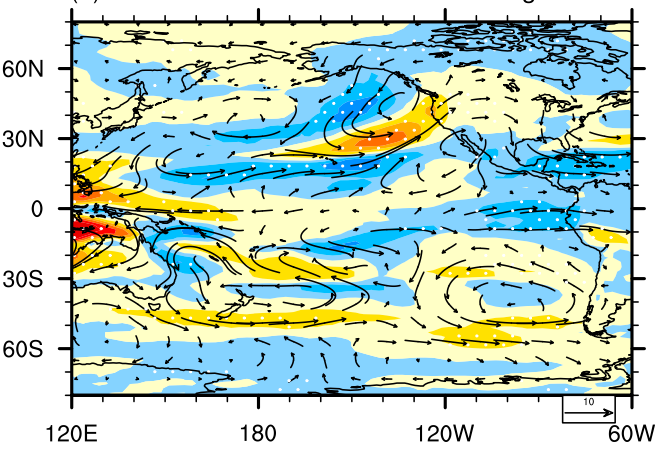

(c) $925 \mathrm{hPa}$ streamfunction \& wind reg to -OLR
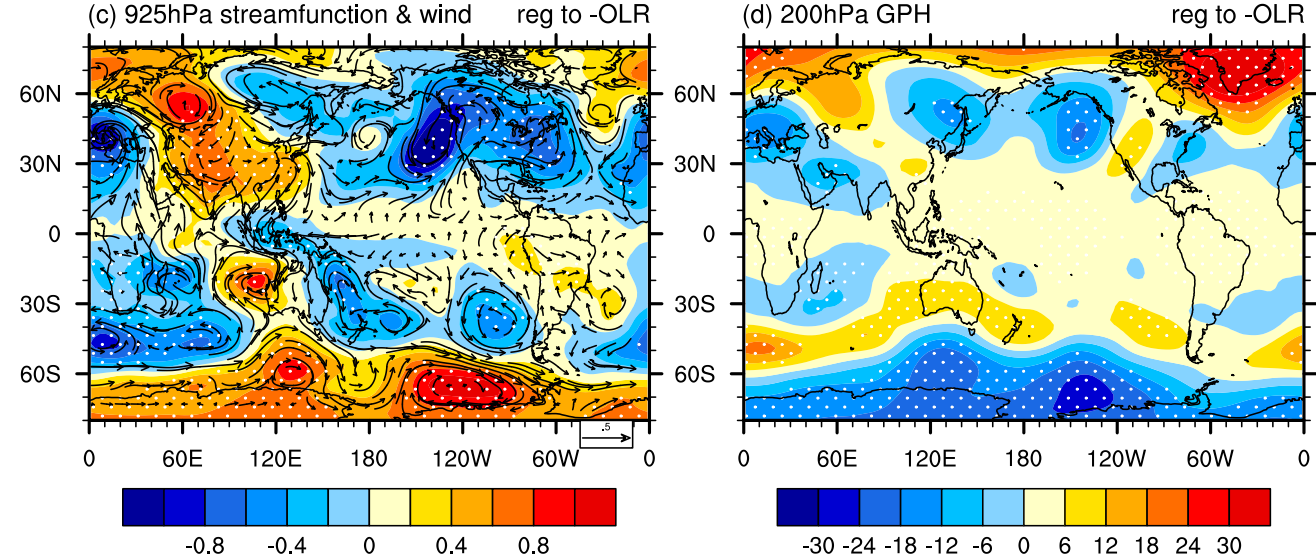

(e) Circumglobal index $\quad 500 \mathrm{hPa}$ GPH reg coef

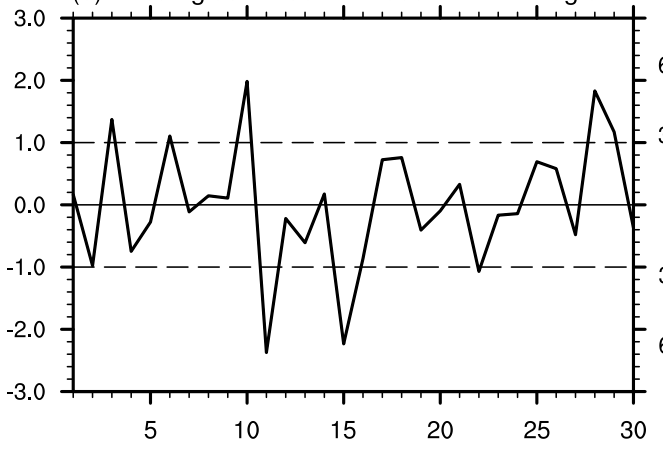

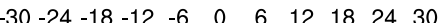
(f) $1000-500 \mathrm{hPa}$ IVT reg to circumglobal index

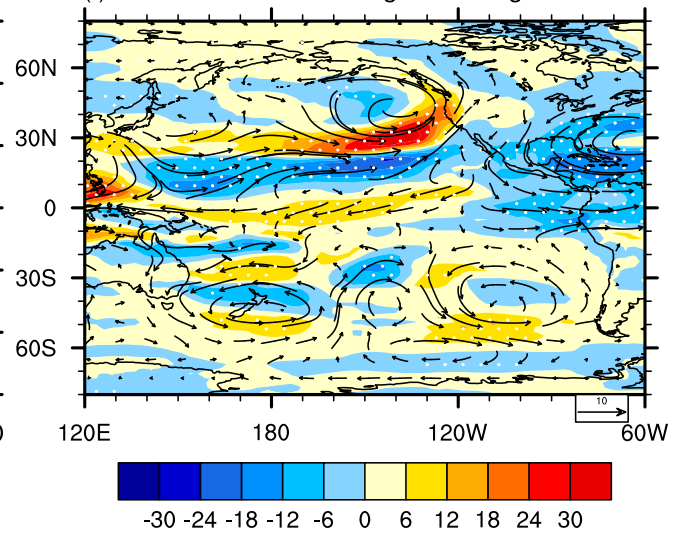

FIG. 10. (a) Standardized negative OLR averaged over $30^{\circ} \mathrm{S}-15^{\circ} \mathrm{N}, 105^{\circ}-130^{\circ} \mathrm{E}$. Regression of (b) IVT $\left(\mathrm{kg} \mathrm{m}^{-1} \mathrm{~s}^{-1}\right)$ vector and magnitude integrated over $1000-500 \mathrm{hPa}$, (c) streamfunction $\left(\times 10^{6} \mathrm{~m}^{2} \mathrm{~s}^{-1}\right)$ and wind vector at $925 \mathrm{hPa}$ $\left(\mathrm{m} \mathrm{s}^{-1}\right)$, and (d) GPH (m) at $200 \mathrm{hPa}$ onto the standardized time series of OLR index in (a). (e) Standardized circumglobal index obtained by regression of GPH at $500 \mathrm{hPa}$ onto the pattern in Fig. $9 \mathrm{~b}$ between $30^{\circ}$ and $70^{\circ} \mathrm{N}$. (f) Regression of IVT $\left(\mathrm{kg} \mathrm{m}^{-1} \mathrm{~s}^{-1}\right)$ vector and magnitude integrated over 1000-500 $\mathrm{hPa}$ onto circumglobal index in (e). All results are based on the DJF mean of monthly outputs of the SSTClim run from GFDL CM3. The dotted areas indicate that the regression coefficients are statistically significant at the $90 \%$ level of confidence.

observations, reanalysis products, and the AGCM outputs focus on the large-scale environment of extreme precipitation variability. The impact of SST forcing on extreme precipitation and its large-scale environment is estimated from the ensemble mean of 54 AMIP runs from the CMIP5 archive. The residual from observations or reanalysis after removal of the ensemble mean is used to understand the impacts of internal atmospheric variability. The main findings are summarized as follows: 

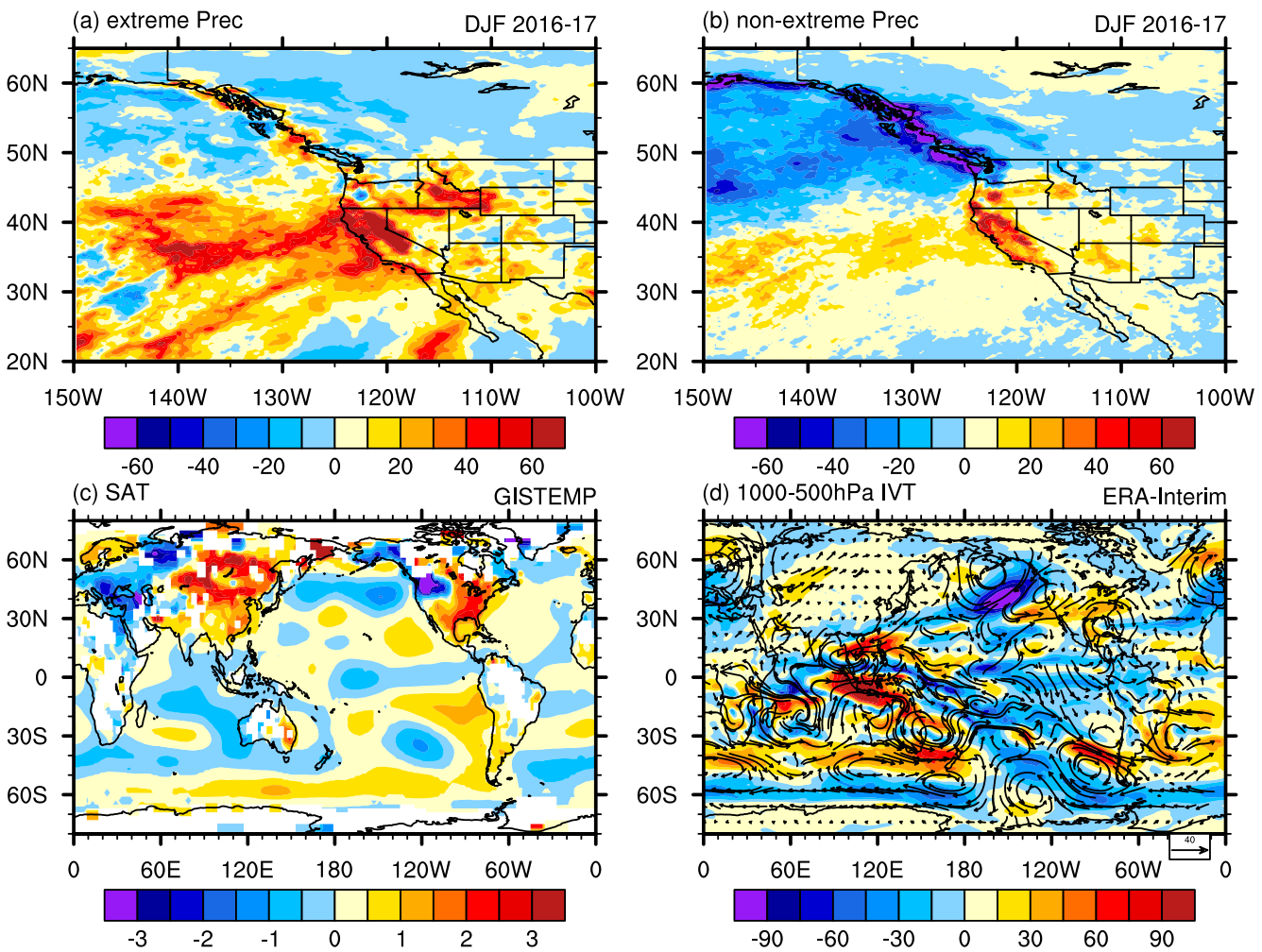

(e) $925 \mathrm{hPa}$ streamfunction ERA-Interim
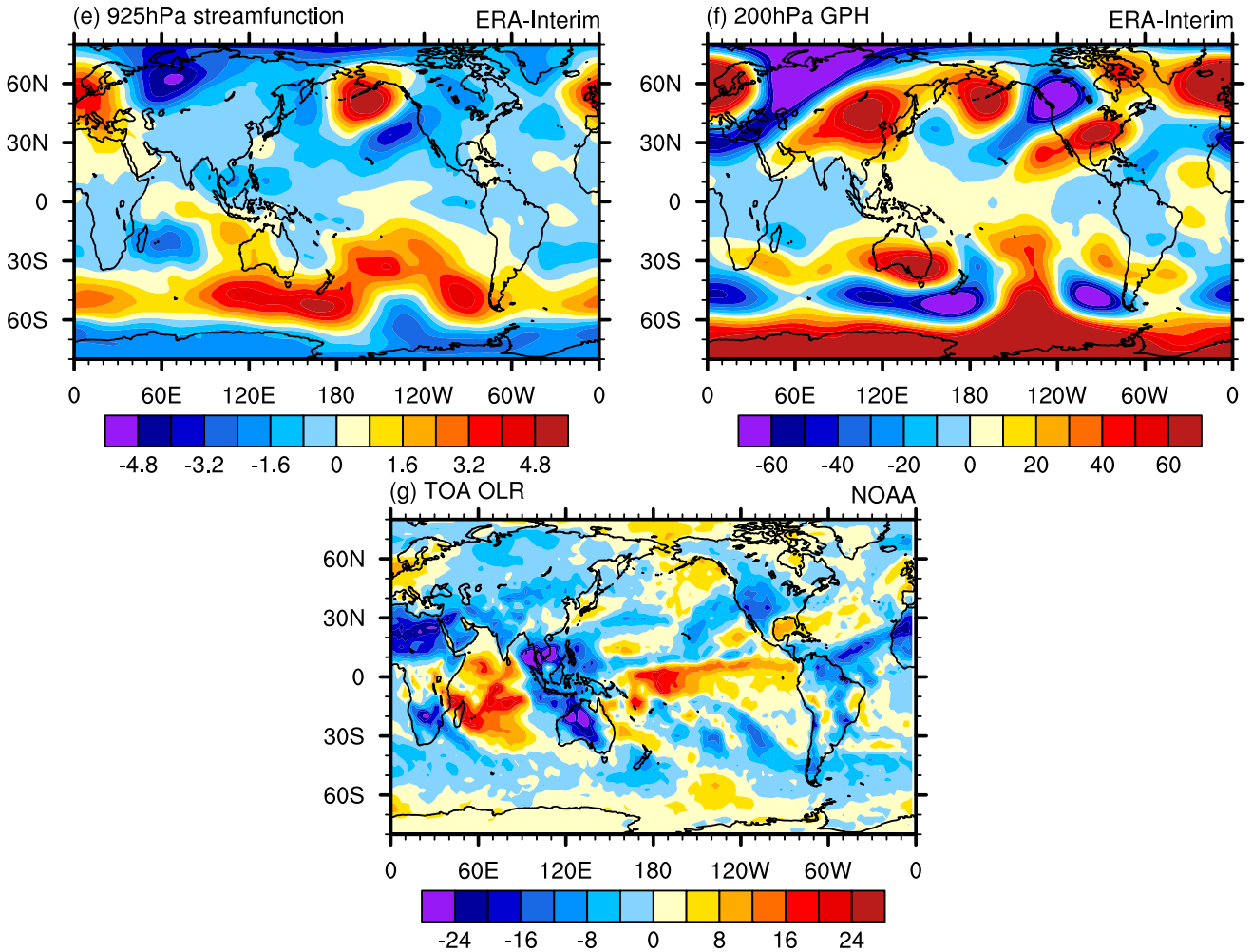

FIG. 11. Anomalies for DJF of 2016/17: (a) extreme precipitation and (b) nonextreme precipitation (mm month $\left.{ }^{-1}\right)$ from NARR, (c) SAT $\left({ }^{\circ} \mathrm{C}\right)$ from GISTEMP, (d) IVT $\left(\mathrm{kg} \mathrm{m}^{-1} \mathrm{~s}^{-1}\right)$ vector and magnitude integrated over 1000-500 hPa from ERA-Interim, (e) streamfunction $\left(\times 10^{6} \mathrm{~m}^{2} \mathrm{~s}^{-1}\right)$ at $925 \mathrm{hPa}\left(\mathrm{m} \mathrm{s}^{-1}\right)$ from ERA-Interim, (f) $\mathrm{GPH}(\mathrm{m})$ at $200 \mathrm{hPa}$ from ERA-Interim, and (g) OLR $\left(\mathrm{W} \mathrm{m}^{-2}\right)$ at the top of atmosphere from NOAA. Note that the linear trend and long-term mean during 1979-2017 have been removed. 
1) SST forcing only accounts for about $20 \%$ of the variances of winter extreme and nonextreme precipitation over the U.S. West Coast. SST forcing influences extreme and nonextreme precipitation through the Pacific-North American teleconnection and North Pacific Oscillation, respectively.

2) Internal atmospheric variability dominates the DJF extreme precipitation, accounting for about $80 \%$ of the total variance. The circumglobal waveguide pattern with a cyclonic circulation located over the U.S. West Coast enhances water vapor transport by ARs and hence, extreme precipitation downstream.

3) The circumglobal teleconnection pattern reflects the intrinsic variability to the mid- to high-latitude atmosphere and it can interact with anomalous convection over the tropical western Pacific. We also demonstrate that strong convection over the tropical western Pacific tends to set the stage for more extreme precipitation along the U.S. West Coast by exciting the circumglobal teleconnection pattern.

4) Atmospheric rivers play a key role in extreme precipitation over the U.S. West Coast (e.g., Ralph et al. 2006; Leung and Qian 2009; Neiman et al. 2011). Both the dominant modes of winter variability of ARs and extreme precipitation feature north-south dipole patterns, and they are significantly correlated. Our analysis shows that SST forcing from the tropical easternto-central Pacific induces a PNA teleconnection with a large cyclonic circulation over the North Pacific that favors high moisture transport by ARs to the western United States. In the absence of SST forcing, a cyclonic circulation over the U.S. West Coast embedded in the wave train of a circumglobal pattern is responsible for the enhanced water vapor transport by ARs. Therefore, ARs are a common and indispensable feature of the large-scale environment that produces concomitant extreme precipitation in the U.S. West Coast.

5) During the winter of 2016/17, multiple ARs made landfall in California, causing record extreme precipitation. Evidence found so far is only suggestive that the record extreme precipitation of 2016/17 was more likely the result of internal atmospheric variability associated with anomalous convection over the Maritime Continent rather than a tropical SST forcing. More rigorous attribution is needed for this speculation in further analysis.

Given the importance of internal atmospheric variability to extreme precipitation on the U.S. West Coast, more research is needed to understand the mechanisms of internal variability and sources of predictability at subseasonal-to-seasonal time scales. More specifically, understanding the optimal atmospheric forcing that excites the circumglobal wave train, particularly the convective heating from the tropical Indian-western Pacific, may hold the key to predicting extreme precipitation along the U.S. West Coast at subseasonal-toseasonal time scales. Recent research identifying the role of land surface anomalies in inducing atmospheric circulation responses through land-atmosphere coupling offers another potential source of predictability of atmospheric variability (Koster et al. 2014, 2016). Because of the multiscale nature of the processes inherent in the tropical-extratropical interactions, and the multiscale processes associated with ARs and the extreme precipitation they produce, high-resolution modeling and high-performance computing may offer unprecedented opportunities for advancing understanding and prediction of extreme precipitation over the U.S. West Coast in the coming decade.

Acknowledgments. This research is supported by the U.S. Department of Energy Office of Science Biological and Environmental Research as part of the Regional and Global Climate Modeling program and the Multi-Sector Dynamics, Earth and Environmental System Modeling program. This work has benefited from helpful discussion with Dr. Bob Houze of PNNL and University of Washington. We appreciate the valuable comments from three anonymous reviewers that have greatly helped improve the quality of this work. PNNL is operated for the Department of Energy by Battelle Memorial Institute under contract DE-AC05-76RL01830. We acknowledge the World Climate Research Programme's Working Group on Coupled Modelling, which is responsible for CMIP, and thank the climate modeling groups listed in Table 1 for producing and making available their model output. The CMIP5 datasets used in this study can be obtained at http://www.ipcc-data.org/sim/ gcm_monthly/AR5/Reference-Archive.html. For CMIP, the U.S. DOE's Program for Climate Model Diagnosis and Intercomparison provides coordinating support and led development of software infrastructure in partnership with the Global Organization for Earth System Science Portals. The authors declare no competing financial interests.

\section{REFERENCES}

Biasutti, M., R. Seager, and D. B. Kirschbaum, 2016: Landslides in West Coast metropolitan areas: The role of extreme weather events. Wea. Climate Extremes, 14, 67-79, https://doi.org/ 10.1016/j.wace.2016.11.004.

Bond, N. A., and G. A. Vecchi, 2003: The influence of the Madden-Julian oscillation on precipitation in Oregon and Washington. Wea. Forecasting, 18, 600-613, https://doi.org/ 10.1175/1520-0434(2003)018<0600:TIOTMO > 2.0.CO;2. 
_- M. F. Cronin, H. Freeland, and N. Mantua, 2015: Causes and impacts of the 2014 warm anomaly in the NE Pacific. Geophys. Res. Lett., 42, 3414-3420, https://doi.org/10.1002/ 2015GL063306.

Branstator, G., 2002: Circumglobal teleconnections, the jet stream waveguide, and the North Atlantic Oscillation. J. Climate, 15, 1893-1910, https://doi.org/10.1175/1520-0442(2002)015<1893: CTTJSW $>2.0 . \mathrm{CO} ; 2$.

—, and H. Y. Teng, 2017: Tropospheric waveguide teleconnections and their seasonality. J. Atmos. Sci., 74, 15131532, https://doi.org/10.1175/JAS-D-16-0305.1.

Cayan, D. R., and L. Riddle, 1992: Atmospheric circulation and precipitation in the Sierra Nevada. Proc. Int. Symp. on Managing Water Resources during Global Change, Reno, NV, American Water Resources Association, 711-719, https:// sfbay.wr.usgs.gov/publications/pdf/cayan_1992_sierra.pdf.

—, K. T. Redmond, and L. G. Riddle, 1999: ENSO and hydrologic extremes in the western United States. J. Climate, 12, 2881-2893, https://doi.org/10.1175/1520-0442(1999)012<2881: EAHEIT $>2.0 . \mathrm{CO} ; 2$.

Chen, X. L., and T. J. Zhou, 2017: Relative contributions of external SST forcing and internal atmospheric variability to July-August heat waves over the Yangtze River valley. Climate Dyn., https://doi.org/10.1007/s00382-017-3871-y.

Chen, Z., B. Gan, L. Wu, and F. Jia, 2018: Pacific-North American teleconnection and North Pacific Oscillation: Historical simulation and future projection in CMIP5 models. Climate Dyn., 50, 4379-4403, https://doi.org/10.1007/s00382-017-3881-9.

Dai, A., J. C. Fyfe, S. P. Xie, and X. Dai, 2015: Decadal modulation of global surface temperature by internal climate variability. Nat. Climate Change, 5, 555-559, https://doi.org/10.1038/ nclimate2605.

Dee, D. P., and Coauthors, 2011: The ERA-Interim reanalysis: Configuration and performance of the data assimilation system. Quart. J. Roy. Meteor. Soc., 137, 553-597, https://doi.org/ 10.1002/qj.828.

Dettinger, M. D., 2011: Climate change, atmospheric rivers, and floods in California-A multimodel analysis of storm frequency and magnitude changes. J. Amer. Water Resour. Assoc., 47, 514 523, https://doi.org/10.1111/j.1752-1688.2011.00546.x.

_ , D. R. Cayan, H. F. Diaz, and D. M. Meko, 1998: North-south precipitation patterns in western North America on interannualto-decadal timescales. J. Climate, 11, 3095-3111, https://doi.org/ 10.1175/1520-0442(1998)011<3095:NSPPIW >2.0.CO;2.

Ding, Q., and B. Wang, 2005: Circumglobal teleconnections in the Northern Hemisphere summer. J. Climate, 18, 3483-3505, https:// doi.org/10.1175/JCLI3473.1.

Gao, Y., J. Lu, L. R. Leung, Q. Yang, S. Hagos, and Y. Qian, 2015: Dynamical and thermodynamical modulations on future changes of landfalling atmospheric rivers over western North America. Geophys. Res. Lett., 42, 7179-7186, https://doi.org/ 10.1002/2015GL065435.

,-- , and — 2016: Uncertainties in projecting future changes in atmospheric rivers and their impacts on heavy precipitation over Europe. J. Climate, 29, 6711-6726, https:// doi.org/10.1175/JCLI-D-16-0088.1.

Guan, B., D. E. Waliser, N. P. Molotch, E. J. Fetzer, and P. J. Neiman, 2012: Does the Madden-Julian oscillation influence wintertime atmospheric rivers and snowpack in the Sierra Nevada? Mon. Wea. Rev., 140, 325-342, https://doi.org/ 10.1175/MWR-D-11-00087.1.

Hagos, S. M., L. R. Leung, J.-H. Yoon, J. Lu, and Y. Gao, 2016: A projection of changes in landfalling atmospheric river frequency and extreme precipitation over western North America from the large ensemble CESM simulations. Geophys. Res. Lett., 43, 1357-1363, https://doi.org/10.1002/ 2015 GL067392.

Hansen, J., R. Ruedy, M. Sato, and K. Lo, 2010: Global surface temperature change. Rev. Geophys., 48, RG4004, https://doi.org/ 10.1029/2010RG000345.

Harnik, N., G. Messori, R. Caballero, and S. Feldstein, 2016: The circumglobal North American wave pattern and its relation to cold events in eastern North America. Geophys. Res. Lett., 43, 11 015-11 023, https://doi.org/10.1002/2016GL070760.

Hartmann, D. L., 2015: Pacific sea surface temperature and the winter of 2014. Geophys. Res. Lett., 42, 1894-1902, https:// doi.org/10.1002/2015GL063083.

He, J., C. Deser, and B. J. Soden, 2017: Atmospheric and oceanic origins of tropical precipitation variability. J. Climate, 30, 3197-3217, https://doi.org/10.1175/JCLI-D-16-0714.1.

Higgins, R. W., and K. C. Mo, 1997: Persistent North Pacific circulation anomalies and the tropical intraseasonal oscillation. J. Climate, 10, 223-244, https://doi.org/10.1175/1520-0442(1997)010<0223: PNPCAA $>2.0 . \mathrm{CO} ; 2$.

Huang, B., and Coauthors, 2015: Extended Reconstructed Sea Surface Temperature version 4 (ERSST.v4). Part I: Upgrades and intercomparisons. J. Climate, 28, 911-930, https://doi.org/ 10.1175/JCLI-D-14-00006.1.

Jones, C., 2000: Occurrence of extreme precipitation events in California and relationships with the Madden-Julian oscillation. J. Climate, 13, 3576-3587, https://doi.org/10.1175/ 1520-0442(2000)013<3576:OOEPEI > 2.0.CO;2.

Jong, B.-T., M. Ting, and R. Seager, 2016: El Niño impact on California precipitation: Seasonality, regionality, and El Niño intensity. Environ. Res. Lett., 11, 054021, https://doi.org/ 10.1088/1748-9326/11/5/054021.

Kalnay, E., and Coauthors, 1996: The NCEP/NCAR 40-Year Reanalysis Project. Bull. Amer. Meteor. Soc., 77, 437-471, https:// doi.org/10.1175/1520-0477(1996)077<0437:TNYRP>2.0.CO;2.

Karl, T. R., and Coauthors, 2015: Possible artifacts of data biases in the recent global surface warming hiatus. Science, 348, 14691472, https://doi.org/10.1126/science.aaa5632.

Kosaka, Y., and H. Nakamura, 2006: Structure and dynamics of the summertime Pacific-Japan teleconnection pattern. Quart. J. Roy. Meteor. Soc., 132, 2009-2030, https://doi.org/10.1256/qj.05.204.

Koster, R. D., Y. Chang, and S. D. Schubert, 2014: A mechanism for land-atmosphere feedback involving planetary wave structures. J. Climate, 27, 9290-9301, https://doi.org/10.1175/ JCLI-D-14-00315.1.

, H. Wang, and S. D. Schubert, 2016: Impacts of local soil moisture anomalies on the atmospheric circulation and on remote surface meteorological fields during boreal summer: A comprehensive analysis over North America. J. Climate, 29, 7345-7364, https://doi.org/10.1175/JCLI-D-16-0192.1.

Kumar, A., and M. Chen, 2017: What is the variability in US west coast winter precipitation during strong El Niño events? Climate Dyn., 49, 2789-2802, https://doi.org/10.1007/s00382-016-3485-9.

Lamjiri, M. A., M. D. Dettinger, F. M. Ralph, and B. Guan, 2017: Hourly storm characteristics along the U.S. West Coast: Role of atmospheric rivers in extreme precipitation. Geophys. Res. Lett., 44, 7020-7028, https://doi.org/10.1002/2017GL074193.

Lavers, D. A., G. Villarini, R. P. Allan, E. F. Wood, and A. J. Wade, 2012: The detection of atmospheric rivers in atmospheric reanalyses and their links to British winter floods and the large-scale climatic circulation. J. Geophys. Res., 117, D20106, https://doi.org/10.1029/2012JD018027. 
Leung, L. R., and Y. Qian, 2009: Atmospheric rivers induced heavy precipitation and flooding in the western U.S. simulated by the WRF regional climate model. Geophys. Res. Lett., 36, L03820, https://doi.org/10.1029/2008GL036445.

Liebmann, B., and C. A. Smith, 1996: Description of a complete (interpolated) outgoing longwave radiation dataset. Bull. Amer. Meteor. Soc., 77, 1275-1277, https://doi.org/10.1175/ 1520-0477-77.6.1274.

Mesinger, F., and Coauthors, 2006: North American Regional Reanalysis. Bull. Amer. Meteor. Soc., 87, 343-360, https://doi.org/ 10.1175/BAMS-87-3-343.

Mo, K. C., and R. W. Higgins, 1998: Tropical convection and precipitation regimes in the western United States. J. Climate, 11, 2404-2423, https://doi.org/10.1175/1520-0442(1998)011<2404: TCAPRI $>2.0 . \mathrm{CO} ; 2$.

Morice, C. P., J. J. Kennedy, N. A. Rayner, and P. D. Jones, 2012: Quantifying uncertainties in global and regional temperature change using an ensemble of observational estimates: The HadCRUT4 dataset. J. Geophys. Res., 117, D08101, https:// doi.org/10.1029/2011JD017187.

Neiman, P. J., F. M. Ralph, G. A. Wick, Y.-H. Kuo, T.-K. Wee, Z. Ma, G. H. Taylor, and M. D. Dettinger, 2008: Diagnosis of an intense atmospheric river impacting the Pacific Northwest: Storm summary and offshore vertical structure observed with COSMIC satellite retrievals. Mon. Wea. Rev., 136, 4398-4420, https://doi.org/ 10.1175/2008MWR2550.1.

— L. J. Schick, F. M. Ralph, M. Hughes, and G. A. Wick, 2011: Flooding in western Washington: The connection to atmospheric rivers. J. Hydrometeor., 12, 1337-1358, https://doi.org/ 10.1175/2011JHM1358.1.

Payne, A. E., and G. Magnusdottir, 2015: An evaluation of atmospheric rivers over the North Pacific in CMIP5 and their response to warming under RCP 8.5. J. Geophys. Res. Atmos., 120, 11 173-11 190, https://doi.org/10.1002/2015JD023586.

Piechota, T. C., and J. A. Dracup, 1996: Drought and regional hydrologic variation in the United States: Associations with the El Niño-Southern Oscillation. Water Resour. Res., 32, 1359-1373, https://doi.org/10.1029/96WR00353.

Ralph, F. M., and M. D. Dettinger, 2012: Historical and national perspectives on extreme West Coast precipitation associated with atmospheric rivers during December 2010. Bull. Amer. Meteor. Soc., 93, 783-790, https://doi.org/10.1175/BAMS-D-11-00188.1.

_ P. J. Neiman, and G. A. Wick, 2004: Satellite and CALJET aircraft observations of atmospheric rivers over the eastern North Pacific Ocean during the winter of 1997/98. Mon. Wea. Rev., 132, 1721-1745, https://doi.org/10.1175/1520-0493(2004)132<1721: $\mathrm{SACAOO}>2.0 . \mathrm{CO} ; 2$.

,,--- S. I. Gutman, M. D. Dettinger, D. R. Cayan, and A. B. White, 2006: Flooding on California's Russian River: Role of atmospheric rivers. Geophys. Res. Lett., 33, L13801, https://doi.org/ 10.1029/2006GL026689.

$\longrightarrow,-$, G. N. Kiladis, K. Weickmann, and D. W. Reynolds, 2011: A multiscale observational case study of a Pacific atmospheric river exhibiting tropical-extratropical connections and a mesoscale frontal wave. Mon. Wea. Rev., 139, 1169-1189, https:// doi.org/10.1175/2010MWR3596.1.

Rayner, N. A., D. E. Parker, E. B. Horton, C. K. Folland, L. V. Alexander, D. P. Rowell, E. C. Kent, and A. Kaplan, 2003: Global analyses of sea surface temperature, sea ice, and night marine air temperature since the late nineteenth century. J. Geophys. Res., 108, 4407, https://doi.org/10.1029/2002JD002670.

Redmond, K. T., and R. W. Koch, 1991: Surface climate and streamflow variability in the western United States and their relationship to large-scale circulation indices. Water Resour. Res., 27, 2381-2399, https://doi.org/10.1029/91WR00690.

Seager, R., M. Hoerling, S. Schubert, H. Wang, B. Lyon, A. Kumar, J. Nakamura, and N. Henderson, 2015: Causes of the 2011-14 California drought. J. Climate, 28, 6997-7024, https://doi.org/ 10.1175/JCLI-D-14-00860.1.

Shields, C. A., and J. T. Kiehl, 2016: Atmospheric river landfalllatitude changes in future climate simulations. Geophys. Res. Lett., 43, 8775-8782, https://doi.org/10.1002/2016GL070470.

,-- , and G. A. Meehl, 2016: Future changes in regional precipitation simulated by a half-degree coupled climate model: Sensitivity to horizontal resolution. J. Adv. Model. Earth Syst., 8, 863-884, https://doi.org/10.1002/2015MS000584.

Song, F. F., and T. J. Zhou, 2015: The crucial role of internal variability in modulating the decadal variation of the East Asian summer monsoon-ENSO relationship during the twentieth century. J. Climate, 28, 7093-7107, https://doi.org/10.1175/ JCLI-D-14-00783.1.

Steinman, B. A., M. E. Mann, and S. K. Miller, 2015: Atlantic and Pacific multidecadal oscillations and Northern Hemisphere temperatures. Science, 347, 988-991, https://doi.org/10.1126/ science. 1257856.

Taylor, K. E., R. J. Stouffer, and G. A. Meehl, 2012: An overview of CMIP5 and the experiment design. Bull. Amer. Meteor. Soc., 93, 485-498, https://doi.org/10.1175/BAMS-D-11-00094.1.

Teng, H. Y., and G. Branstator, 2017: Causes of extreme ridges that induce California droughts. J. Climate, 30, 1477-1492, https:// doi.org/10.1175/JCLI-D-16-0524.1.

, H. L. Wang, G. A. Meehl, and W. M. Washington, 2013: Probability of US heat waves affected by a subseasonal planetary wave pattern. Nat. Geosci., 6, 1056-1061, https://doi.org/ 10.1038/ngeo1988.

Warner, M. D., and C. F. Mass, 2017: Changes in the climatology, structure, and seasonality of northeast Pacific atmospheric rivers in CMIP5 climate simulations. J. Hydrometeor., 18 , 2131-2141, https://doi.org/10.1175/JHM-D-16-0200.1.

_ _ _ a and E. P. Salathé, 2012: Wintertime extreme precipitation events along the Pacific Northwest coast: Climatology and synoptic evolution. Mon. Wea. Rev., 140, 2021-2043, https:// doi.org/10.1175/MWR-D-11-00197.1.

,-- , and -2015 : Changes in winter atmospheric rivers along the North American West Coast in CMIP5 climate models. J. Hydrometeor., 16, 118-128, https://doi.org/10.1175/ JHM-D-14-0080.1.

Yoon, J.-H., and L. R. Leung, 2015: Assessing the relative influence of soil moisture and ENSO SST on precipitation predictability over the contiguous United States. Geophys. Res. Lett., 42, 5005-5013, https://doi.org/10.1002/2015GL064139.

Zhou, S., M. L'Heureux, S. Weaver, and A. Kumar, 2012: A composite study of the MJO influence on the surface air temperature and precipitation over the continental United States. Climate Dyn., 38, 1459-1471, https://doi.org/10.1007/ s00382-011-1001-9.

Zhu, Y., and R. E. Newell, 1998: A proposed algorithm for moisture fluxes from atmospheric rivers. Mon. Wea. Rev., 126, 725-735, https:// doi.org/10.1175/1520-0493(1998)126<0725:APAFMF>2.0.CO;2. 